\title{
A Theoretical Relationship Between Guardianship and Techniques of Neutralization: A Qualitative Analysis of Digital Piracy
}

Christopher D. Davies

West Virginia University

Follow this and additional works at: https://researchrepository.wvu.edu/etd

\section{Recommended Citation}

Davies, Christopher D., "A Theoretical Relationship Between Guardianship and Techniques of Neutralization: A Qualitative Analysis of Digital Piracy" (2012). Graduate Theses, Dissertations, and Problem Reports. 839.

https://researchrepository.wvu.edu/etd/839

This Thesis is protected by copyright and/or related rights. It has been brought to you by the The Research Repository @ WVU with permission from the rights-holder(s). You are free to use this Thesis in any way that is permitted by the copyright and related rights legislation that applies to your use. For other uses you must obtain permission from the rights-holder(s) directly, unless additional rights are indicated by a Creative Commons license in the record and/ or on the work itself. This Thesis has been accepted for inclusion in WVU Graduate Theses, Dissertations, and Problem Reports collection by an authorized administrator of The Research Repository @ WVU. For more information, please contact researchrepository@mail.wvu.edu. 
A Theoretical Relationship Between Guardianship and Techniques of Neutralization: A Qualitative Analysis of Digital Piracy

\author{
Christopher D. Davies
}

\begin{abstract}
Thesis submitted to the Eberly College of Arts and Sciences

At West Virginia University

In partial fulfillment of the requirements

for the degree of
\end{abstract}

\author{
Master of Arts \\ In \\ Applied Social Research \\ Corey Colyer Ph.D. Chair \\ Jason Manning Ph.D. \\ Rachel Stein Ph.D.
}

Department of Sociology and Anthropology

Morgantown, West Virginia 2012

Keywords: Neutralization, Digital Piracy, Routine Activities theory, Guardianship

Copyright 2012 Christopher D. Davies 


\section{ABSTRACT \\ A Theoretical Relationship Between Guardianship and Techniques of Neutralization: A Qualitative Analysis of Digital Piracy}

\section{Christopher D. Davies}

This research is a qualitative analysis of digital piracy at the height of Napster in 1999. The findings support the notion that technology has given rise to several new techniques of neutralization. In some cases these techniques are completely new and in others they are $21^{\text {st }}$ century updates to traditional techniques. Furthermore, this research uses forum posts from USENET to determine that guardianship as created by Cohen and Felson's Routine Activities Theory is uniquely connected to neutralization based on two unique guardianship qualities, authority and capacity. 


\section{TABLE OF CONTENTS}

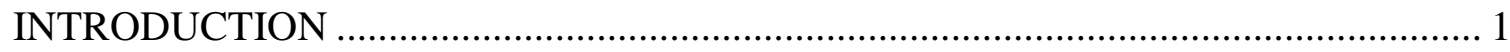

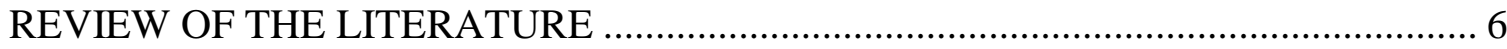

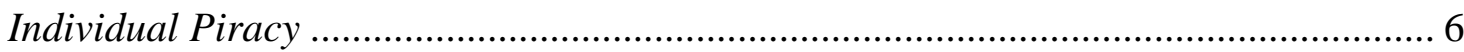

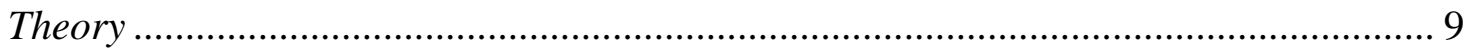

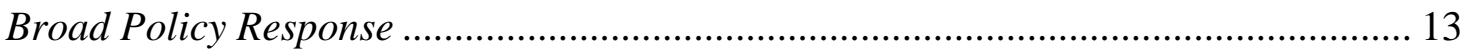

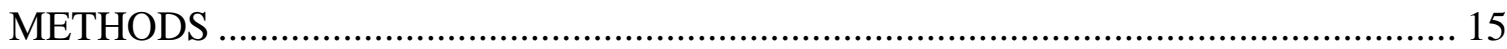

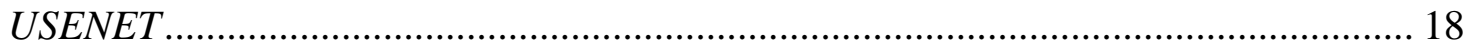

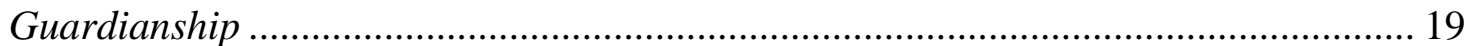

Coding the Traditional and New Techniques of Neutralization .................................. 20

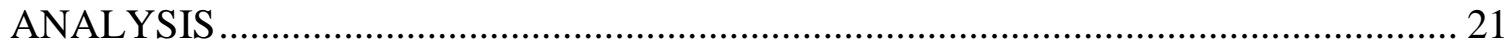

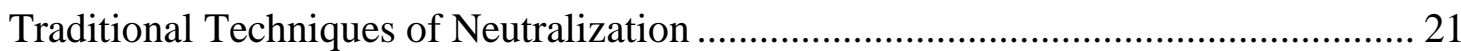

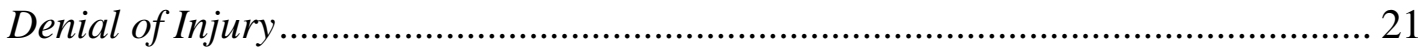

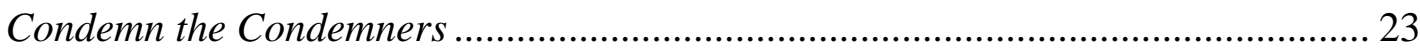

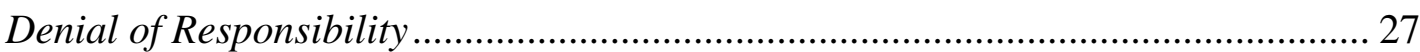

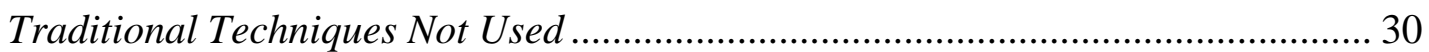

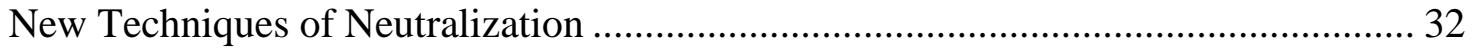

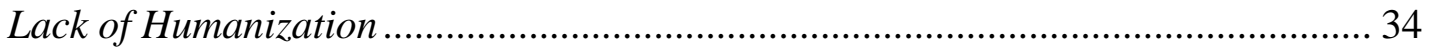

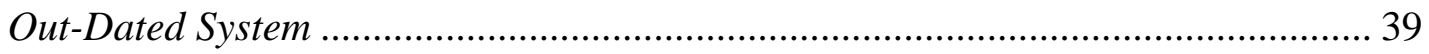

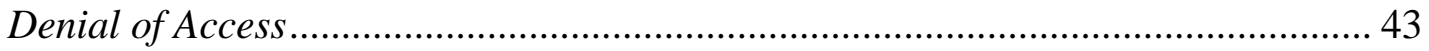

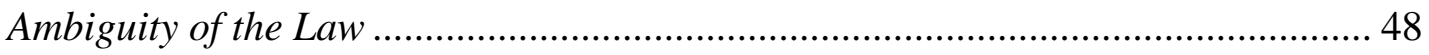

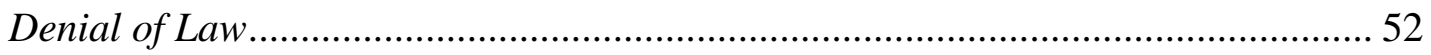

LIMITATIONS AND FUTURE RESEARCH..................................................... 56

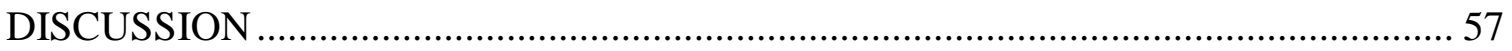

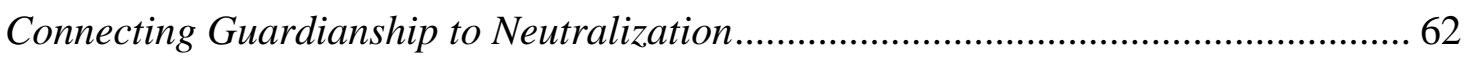

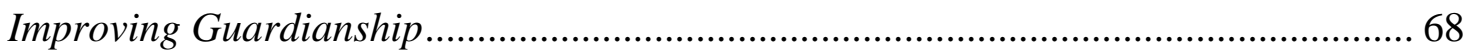

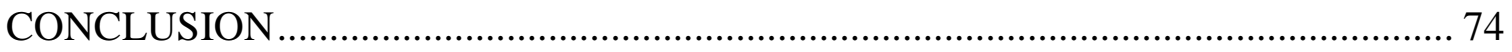

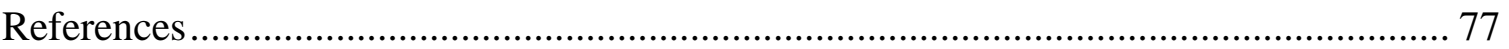


Piracy, the illegal duplication of copyrighted materials that is shared and/or sold, is something that has always plagued the media industry. In the early 1980s, pirates would use boom boxes to copy the music and then sell it or use the U.S. postal service to send it to friends (Moore 2010). It is something that used to be hard to do and required a lot of time. However, technology has allowed pirates to duplicate and share music in a matter of minutes to literally millions of people over the internet. (Holsapple and Iyengar 2008). Music piracy may seem insignificant to other crimes but it is a type of deviance that is becoming increasing common. The first cases of piracy came in the early 2000s and nothing has been successful at slowing its momentum. On a college campus students simply ask where to illegally download it rather than where to buy it. Technology will continue to change our world and allow us to do things we never before thought possible - and the same is true for deviants and criminals. Things that were previously only physical such as books, music, movies, magazines, and newspapers also have a digital counterpart. After 244 years of existence, the Encyclopedia Britannica halted the printed presses in 2012 and became a 'digital only' resource (Haq 2012). We could see potential problems when digitation spreads to other mediums. Even more so when you consider newer mediums are only digital, such as mobile phone "Apps." Apps are a multibillion dollar business that pirates are beginning to take advantage of. If policy makers were to understand why pirates commit this crime and how they neutralize their behavior we may be able to formulate policies that prevent piracy from occurring on different mediums in the future.

Despite being completely illegal, digital piracy has continued to thrive. After nearly two decades of existence the courts have been unsuccessful at creating policy that substantially decreases the amount of digital piracy in the United States. This research aims to modernize traditional techniques of neutralization as well as create a theoretical relationship between the 
effects of guardianship and neutralizations utilized. Matza and Syke's Techniques of Neutralization was created in 1964 and is nearly 50 years old. It remains effective at explaining justifications provided for in the physical space, but technological innovations have created a cyber space in which an increasing amount of society interacts. As we progress through the digital age it is imperative we understand technology and the internet's effect on neutralizations. Furthermore, if the courts wish to be successful at combating digital piracy they must first understand how digital pirates neutralize their behavior. Understanding justifications will allow law enforcement, the courts, and record labels to employ and improve the guardians at play that could eventually decrease piracy rates.

Media piracy is not something new to the internet, technological advancements have simply made it increasingly easier to commit. With the advent of person to person networks (p2p), such as Napster, it was taken from a highly technical task to something almost anyone with a computer and modem could do. Most studies have focused on the 2000s and few utilize longitudinal studies starting in the early 1990s. There is not much data available for digital piracy before the early 1990s and late 1980s. Even though it has been occurring for a while, it did not get mainstream attention until bassist Lars Ulrich of Metallica sued one of the first $p 2 p$ sharing network companies, Napster. After this suit piracy was discussed everywhere and became the 'hot topic' on news television shows. This is in part because it was not until this time that the public realized that the media industry was reporting losing well over $\$ 1$ billion in revenue (Ahmad et al. 2009). Today it is believed that the total cost (pirated material, job loss, effect on companies, etc.) is $\$ 59$ billion, which represents a $2 \%$ increase from 2008 . The widely accepted belief is that this lost revenue is directly related to media piracy. 
According to the Business Software Alliance (via Holesapple and Iyengar 2008) if policy makers were able to slow down piracy by $10 \%$ a year, over a 4 year span, it could create as many as 1 million new jobs and $\$ 400$ million in revenue, based solely on the retail value of pirated material. They also indicate that in 2003 in the United States an estimated 36\% of all software was pirated which resulted in approximately $\$ 29$ billion in revenue (Brune, et al 2007). Surprisingly, this appears to be the lowest legal to illegal download ratio in the world. In places such as Italy and Spain, over 85\% of all software is illegally pirated (Givon, et al. 1995).

Another problem with media piracy is that it is a deregulated area of law. It is something that is clearly defined as illegal but there are not many agencies that are responsible to pursue investigations and legal actions (Dent 2009). Dent's work gives us great insight to copyright infringement law and how it makes piracy more accessible. There have been attempts to regulate such as the No Electronic Theft (NET) Act, Digital Millennium Copyright Act (DMCA), and most recently the Combating Online Infringement and Counterfeit Act of 2010. These laws define what is illegal and the powers of government, but leave much to be desired when it comes to enforcement and agency control.

Even though there are substantial economic consequences to media piracy there are many more problems that aren't directly related to money. Sociologists and criminologists are trying to discover where there are different belief systems among individuals on shoplifting and "softlifting," the stealing of digital material (Brune, et al 2007).

Research has also been performed that looks at the individual and the reasons they pirate. Unfortunately, much of this research is decentralized and fragmented. Few of these studies look at the phenomena as whole; rather they are looking in depth at particular problems within the field. This is great for gaining an understanding in different areas but does not allow us to see the 
totality of these variables combined. Some research forgets that there is more to it than just their particular research interests.

Past research has well documented who is committing piracy, why they commit piracy, and factors that lead to piracy. Most of this research only displays economical and business aspects while not considering the sociology and criminology of piracy. This area of study would be greatly benefited with a study that focuses on techniques of neutralization and routine activities theories. These classical theories were once only applied to "physical" crimes, they have not been dis/proven to be effective at more modern virtual crimes. This research will apply these two theories to digital piracy to see exactly how pirates are able to neutralize their behavior in the $21^{\text {st }}$ century as well as gain an understanding of the role of guardianship.

Although the business literature does provide insight on digital piracy, it does so very pragmatically. They are more interested in the cause-effect relationship and ignore other factors that play an important role. Demographics are important but figuring out why these college aged males, in particular, are pirating is even more beneficial. It is far easier to explain piracy when only thinking about the individual. When complex ideas like institutions, the rest of society, and laws come into play the picture gets progressively more blurry.

The sociological perspective takes more into account than simply whom and what practical matters are at play. Human relationships and society play a large role in our decision to do things. Those who pirate are operating in a structure bigger than just themselves; they don't exist in a vacuum. When deviance occurs, it is better to look at the entire picture rather than a specific incidence. Understating digital piracy through a sociological lens will allow us to see what other factors are at play and what would be the best way to stop them before they get a chance to start. This research capitalizes off of this and looks specifically at techniques of 
neutralizations, capable guardians, and their complex relationship. If we fully understand the role of guardianship in piracy more can be done to prevent it from occurring in the first place. A pragmatic view would only allow you to stop the problem once it starts without getting to the root of it.

Computers allow people to act in the privacy of their home with nothing to really stop their online actions. Many people who pirate music are "normal law abiding" citizens. They don't go out to Wal-Mart and steal music, but at the same time they have set a double standard on the virtual goods. They have a unique opportunity structure that routine activities will demonstrate allows for their deviant behavior while techniques of neutralizations will show us why they feel their crimes are not deviant.

This research capitalizes on the high profile attention given to Napster. Napster is truly the landmark narrative for the downfall of person to person networks. A landmark narrative is a typifying example of a particular phenomenon (Nichols 1997). When Metallica sued Napster this was the first time that many people had heard about piracy and the story seemed to be on every media station in the country. In fact, Metallica suing Napster helped the media create a broader relevance because of Metallica's popularity and the media storm it created. Such a high profile group combined with an attentive media allowed this relatable narrative to take place. Other $\mathrm{p} 2 \mathrm{p}$ companies such as LimeWire have been sued since but have not received the same exposure as Napster. The case involving Napster created a unique digital conversation captured on internet forums. Using Usenet, I will examine people's beliefs on Napster and how they are able to neutralize their behavior.

Specifically this research proposes to explain piracy by examining the opportunity structure explained by routine activities theory and using techniques of neutralization. Research 
has already shown possible explanations for piracy such as cost and availability but it does not explain how the internet has created a unique opportunity for people to commit this crime. It presents opportunities that the 'normal law abiding citizen' uses to get intellectual property for free while still being able to have a clear conscious using various neutralization techniques to decriminalize their behavior.

The analysis that follows demonstrates that techniques of neutralization, as originally written, are still applicable to the digital age, but some require a technological enhancement while new groups have been created. The people that have neutralized their behavior in the USENET forum have begun to use techniques of neutralizations that were not previously documented. The posters of this forum also give a greater insight to guardianship qualities, such as authority and capacity, to greater understand an emerging relationship between neutralization employed and the guardian at play.

\section{REVIEW OF THE LITERATURE}

\section{Individual Piracy}

Most research focuses on piracy at the sub national level, with most of it focusing on the individual who is pirating. Research suggests that there are numerous stakeholders and an individual profile that has been created to figure out who will be committing piracy. It is important to see who piracy effects as well as who is committing piracy if we are ever going to be able to slow down piracy. Once we are able to accurately predict who is pirating the companies and governments involved, the stakeholders, will be able to cooperate and create new policy.

Gould and Pola's research looks at the consumer, the marketer, and the government's role in software piracy (2004). The marketers must decide whether or not to pursue or ignore 
piracy while the government must decide how existing laws are applied to new technology. The government must also find a way to get involved with the prosecution of these individuals (Gould and Pola 2004). Out of the three the consumer has the most difficult questions. Gould and Pola look at the economic, ethical, legal, and awareness decisions that the consumer has to make (2004). Their results indicate that policy should be created with heavy emphases on ethics and morality. In other words, the consumer should understand the relationship of their own ethical and moral stand point in relationship to the law. An effective law would mirror their ethics and morality thus discouraging them from performing the deviant behavior (Gould and Pola 2004). However, before enacting policy that targets a specific type of belief in morality there must be a consensus on who is doing the pirating.

Previous research suggests that there is a growing demand for a "profile" of the typical software pirate. One study has gotten at least four predictors that have proven successful. They have found that upperclassmen college males are more likely to pirate software than other groups (Cheng et al. 1996). It has also been shown that computer literacy may play a role in someone's likelihood of pirating. Obviously, an expert is more likely pirate than a novice (Cheng et al. 1996). These are great predictors of piracy but they have only been found to be accurate within small colleges. A major limitation is that these types of studies are focused on individual institutions and it is difficult to see if these trends are occurring on other college campuses in the same fashion as they are at their particular one. A national survey or at least a project that synthesis similar piracy research into a larger national picture needs to occur before we can say that there are predictors on a national level.

Recently, researchers believe that the group Cheng identified as the pirates "profile" is "Generation Y" (Freestone and Mitchell 2004). "Generation Y" is the first generation that has 
grown up with computers and the internet almost always being available. In this study they extensively look at the connection between this generation and their ethics when it comes to online piracy. They collected data from 12 focus groups to begin writing their questionnaire that helped refine it to a point where they had a final sample of 219 "Generation Y consumers" (Freestone and Mitchell 2004). Their sample is relevant because they define Generation Y as 1821 year olds who are familiar with the Internet. In the end, Freestone and Mitchell find that they believe that consumers are more likely to commit this kind of crime because there are no direct consequences (2004). They did not get in trouble for it and they don't see any economic decline from major record labels. This appears to be one of the better measuring sticks for gathering a population. Almost all studies in the field of piracy have focused on college students.

The result of Freestone and Mitchell work is complimented by a study that examined the factors that lead to piracy (2004). While Freestone and Mitchell looked at primarily age and why a student would pirate, this research is focused on predictive behavior. Al-Rafee and Cronon studied 292 individuals to look for predictive behavior of software piracy (2008). They looked at software piracy beliefs as well as previous actions. They found that an individual's favorable attitude as well as previous experience pirating had the greatest effects on piracy rates (Al-Rafee and Cronon 2008). This is concerning because there are so many people who have favorable beliefs towards piracy. They have found that individuals who maintain a negative outlook on piracy would be less likely to actually pirate something.

Together Freestone and Mitchell and Al-Rafee and Cronon research help give an idea of whom and why college students are pirating music and software (2008). Together they lead us in a direction to be more specific with our research. However, a major limitation is that they suggest that a favorable opinion of piracy leads to action. This brings up more questions than it 
answers. First off, why do they have a favorable opinion of an illegal activity? It's not very often you hear people say that they like who people steal things. This brings up the virtual vs. real product debate. What fundamental difference creates opinion? Secondly, what is the trigger for action? In other words, we all want a Ferrari but very few of us act on impulse and steal one. What takes a favorable opinion of something to illegal action? Further research must distinguish why students think is okay and why they act on these impulses.

The field consensus that college students are the major pirating group has become more and more apparent. Almost all research focuses directly on college students. To add to the general knowledge of college piracy, longitudinal studies are able to see if there are differences among college students over time. Eining and Woolley's research used responses from 481 accounting students at an American University (2006). They performed a replicate study from 1991 to compare results. Their results show that even though piracy is popular, the rates aren't as high as they were in 1991 as compared to 2003. However, this data might be misleading because there is more digital information available now than in 1991. This means that even though the same amount of people may be downloading, their rates could be higher because of increased accessibility.

\section{Theory}

Although the problem of software and media piracy crosses many different academic disciplines, sociologist and criminologist have been interested in analyzing the problem with different sociological theories. Other disciplines mostly research the who and not the why. For businesses, it does not matter why they are doing it as much it does to figure out who is doing it. This way, they are able to specifically target groups of people.

One of the more widely accepted theories that helps explain software piracy is social learning theory. This is especially true for explaining piracy in terms of college students (Fream 
1997). The four components of social learning theory are, close contact, imitation of superiors, understanding of concepts, and role model behavior, can all be applied to piracy. Fream found that students are able to learn from each other and continue to participate in this deviant behavior (1997). They also found that many students acknowledge that their actions are illegal but that still does not deter them (Fream 1997). This again asks the same questions as Al-Rafee and Cronon's research. What makes students go from a favorable opinion to illegal action?

Routine activities theory and techniques of neutralization could help answer this complex question. As Yar's research will demonstrate, routine activities theory has been successfully applied to cybercrime in general but not specifically to digital piracy (2005). The opportunity structure that the internet provides could make it easier for pirates to make the decision to download music rather than legally buy it. This research will focus on both routine activities and techniques of neutralization.

Cohen and Felson's research to explain urban crime in the late 1970s laid the groundwork for them to develop routine activities theory. Although their work is done with physical contact in mind, their ideas should still apply to the modern age internet. The three main facets of routine activities are a motivated offender, suitable target, and the absence of a capable guardian (Cohen and Felson 1979). In this theory a motivated offender would be anyone that is a capable of committing a crime. A suitable target is a target that is a soft target that the motivated offender will commit the crime against. While the last facet, capable guardian, would be any person that would deter the criminal from committing the crime. It does not necessarily have to be a police officer or a person of authority. A group of people could act as a deterrent. A person's moral system and values could even act as a guardian because they typically don't allow for certain 
behaviors. In essence, they are able to 'guard themselves.' An absence of any of these three components creates the opportunity structure in which crime is able to occur.

Routine activities theory has already been applied to cybercrime in general. Routine activities theory suggests that social situations that cybercriminals find themselves are what lead to the deviant behavior (Yar 2005). When motivated offenders are identified, the deregulation of the laws plays a role in removing a capable guardian. There is a debate if there even are capable guardians in cyber space. Even though there are differences between the "real word" and "cyberspace" the 'organization of time and space' is still key to routine activities and cybercrime (Yar, 2005; 424). Even though he argues that traditional definitions of the three facets of routine activities theory need to be adjusted to meet the demands of a changing world, it might still fit. This study takes routine activity theory and applies it in a new way but it does not look specifically at different types of cybercrime. Cybercrime could range from anything to white collar crime to computer hacking. Research that breaks down cybercrime into different areas and looking at its relationship to routine activities theory is something that could benefit this area of research. Researchers may find that routine activities does not hold true for all types of cybercrime.

Techniques of neutralization are also used to help understand piracy but the theory is not used often. Despite not being applied often in previous research, this could be one the best at understanding piracy, especially when it is combined with others which allows for greater insight on digital piracy. Morris and Higgins found that out of all of the theories they tried to apply, techniques of neutralization were the most statistically significant (2008). However, it did not help explain all formats of digital piracy such as the music, software, movies, and other formats. They also found that neutralization techniques could not help predict future piracy (Morris and 
Higgins 2006). I believe, much like the researchers, that this would be one of the most helpful theories in explaining digital piracy. While looking at mostly criminological theories it is interesting that they do not look at techniques of neutralization and routine activities theory combined affect on piracy, which is something that this research intends to do.

Techniques of neutralization were first applied by Sykes and Matza in their research on delinquency. They begin by rejecting the notion that most deviant individuals view their behaviors as morally correct. Instead they propose that even some criminals experience guilt over their actions (Matza and Sykes 1957). They also provide some 'moral codes' that criminals can live by to show that they themselves may not believe they are completely deviant. For example, they offer the example of not stealing from friends or committing vandalism against a church (Matza and Sykes 1957, p 665). These rough moral codes allow them to continue their behavior while not feeling as guilty. To this extent, Matza and Sykes also begin to form the techniques of neutralization based upon the fact that if they are able to avoid "moral culpability" for their actions, they are more likely to participate in deviant behavior (1957).

Generally, there are five major types of techniques of neutralization—denial of responsibility, denial of injury, denial of a victim, condemnation of the condemner, and an appeal to higher loyalties. These defense strategies allow the offender to maintain a moral high ground and consider themselves as bending the rules rather than completely breaking them (Matza and Sykes 1957). Of course, when Sykes and Matza wrote the theory in the late 1950s this strictly applied to our 'physical world.' However, in an increasing digital age this theory can help us explain why otherwise 'normal' law abiding citizens will commit cybercrime, and in particularly, the illegal downloading or copying of intellectual property. 


\section{Broad Policy Response}

Although most of the research done in this field deals specifically with causes and relationships with a small emphasis on policy out comes, there are some that deal with specifically how to put an end to software piracy. Digital Rights Management, DRM, is something that was added to a music file to help prevent piracy (Fernando et. Al 2010). If a music file is downloaded and DRM is encrypted into it, there are certain restrictions in place. However, there is debate of whether or not the restrictions are harming the pirate or also the rightful consumer. DRM restricts everyone, regardless of how they downloaded the material. The authors have found that removing DRM actually increases legitimate sales because someone who would pirate for "DRM-Free" music is not willing to pay for the product (Fernando et al 2010). It also lowers the price of the product because there is less work that needs to be done to get it ready for sale. DRM is able to act as a guardian in multiple ways.

First, and least obvious, it lets people know that authority figures are actively trying to combat piracy. A potential pirate that has that thought in the back of their mind may be less likely to pirate than someone who does not consider it. For example, if someone knows a home has specific security measures they would be less likely to commit the crime. Secondly, it is an active guardian in that it is manipulating the digital medium to control the distribution of the digital material. Even if the pirate succeeds in downloading the material this type of guardian may stop them from committing piracy if they don't know how to bypass the security provided by DRM music. In the house example, they would be even less likely to commit the crime if they knew a safe in the house was impenetrable.

One of the most well known anti-piracy tactics was opening digital stores. Places like Amazon.com, Wal-Mart, and iTunes have services that allow the consumer to buy music and media from their home (Robert 2005). Consumers stopped pirating as much when they were able 
to only buy one song for .99 cents. Before peer to peer networks, the only way to receive only one song from a CD was to illegally download it (Robert 2005). The only problem with these methods is that they were discovered as a temporary solution rather than something that could potentially end piracy. Despite a new, technologically innovative market piracy is something that still occurs today. Had these companies created these markets prior to piracy gaining mainstream attention, they might have been able to create a system in which the norm was purchasing digital material rather than pirating it. There have not been any successful measures that stop new pirating tactics before they begin (Roberts 2005).

The simple guardian of having an alternative choice has proven to be widely successful for these digital retailers. Many people think of a guardian as a physical barrier that prevents someone from committing a crime but really it can be anything that deters a crime. When Napster was popular there was no alternative in downloading digital music so if someone wanted something, they had to turn to this service. Right after the Napster case ended iTunes opened their doors and filled the void. Having a legitimate retailer allows people to download digital music legally and attempts to create a norm in which paying for digital goods is the accept route in acquiring ownership.

Economically, studies like Robert's lead us to believe that piracy actually brings down the price of the physical product (Robert 2005). Companies can't compete with the price of "free" but can lower their prices to make them more attractive. If done correctly, pricing can also act as a guardian against digital piracy. If something is priced at what consumers believe it should be, then they would be more likely to simply purchase it rather than deal with the potential consequences of committing a crime. People must believe that they are actually getting their money's worth (Hui-Lee et al. 2005). A study performed by Khouja and Rajagopalan 
suggests that piracy is actually making the price of media and software to increase (2009). In specific examples the authors find that profit maximization and product shelf life play a large role in the price that the consumer pays. If early adapters illegally download the product when it first comes out, late arrivers will be a premium for their late entry. If the product sits on the shelf for too long at their projected price and is not selling they may be more likely to increase the price and make more money off of a single product (Khouja \& Rajagopalan 2009). There still must be a further study to see if these increased prices lead to increased profit. Even though some consumers are paying more, it might not be making up the difference in money lost to pirating.

Although it may seem that there are a numerous responses to piracy, there aren't actually many things that work. As the previous studies have shown, college students simply don't believe that they are going to be caught. Despite all of the active and passive guardians at play, none of them seem to work. In our physical space there are security cameras, witnesses, and physical barriers that prevent theft. Things such as morals and the desire to remain law abiding also play into effect in the decision to steal something. On the internet these guardians don't play a large enough role to deter crime from happening. As this research shows, pirates are able to use new techniques of neutralizations that negate the desired effects of guardianship. There need to be more research in determining what would actually stop people from downloading music. In fact, more research should come in the form of what will actually stop students from illegally downloading material. Survey's that address perception of threat as well as asking about things that would slow piracy would help address this issues.

\section{METHODS}

This research uses a unique data collection method that results in an inside look at how digital pirates use techniques of neutralization. Traditional means of acquiring data would not 
have been suitable for answering this research question, so I have leveraged the USENET archive of digital forums. An internet forum is a preserved digital conversation but has several advantages. An internet forum gives us an indication of what was being discussed about a topic while it occurred. It is literally a digitally recorded conversation that does not rely on memories to be accurate. In some ways, it is like stepping into a time machine and observing a conversation. Although interviews are a proven sociological methodology, when asking about specific conversations in the past they may not prove to be entirely accurate. These internet forums may not be the traditional type of resource that many usually use, but they offer significant advantages that other methodologies cannot provide; a contemporaneous view of a specific topic that was popular over 15 years ago. With this type of data I am able to analyze each post for different types of neutralizations while also looking at their relationships to guardianship.

This technique leverages an archival approach which has the unique ability to uncover a subject's hidden history that might not be accessible through traditional means (Hopton 2007). This research gives a descriptive insight to the types of techniques of neutralizations and their relationship to guardians because of its unique contemporaneous, conversational style. When people speak about why they do things they don't specifically use techniques of neutralization. For example a response would not be, "I illegally download because I am denying there is injury." The internet forums provided a digital conversation that was later coded based on certain attributes of the post, which are explained later in this section.

The forums in this research provided two critical aspects of this thesis. Firstly, being a qualitative project they helped to pinpoint a complete research question based on what is being said on the topic of digital piracy. I had not expected to find several new techniques of 
neutralization but they were presented in the discourse. Secondly, it served as the primary data collection method. The scope of this research is not to examine for profit pirating, but rather the digital piracy habits of the everyday, average citizen. These forums provide a way to understand what was being said about piracy at the time, while it was occurring.

This research utilized an open coding scheme with an inductive approach. A grounded theory methodology suggests that a broad topic that may have a phenomenon we are interested in studying. Simply put, how do you know what is out there if you haven't first taken a look? A completely inductive approach would have been to read through the forums and conduct research on whatever data was collected. The important questions will become clear while analyzing the data and lead to the conceptual framework in which to study them (Miles and Huberman pp 17). This research combines both a deductive and inductive approach. An initial research interest was identified but analyzing the data allowed for a concise research question. I was interested in the techniques of neutralization a pirate used during the era of Napster but was also able to discover several neutralizations unique to internet crimes. Knowing that I was looking for specific techniques of neutralization allowed me to generate of list of attributes I would define as characteristic of that technique. The sections of data that met this criterion were coded to represent a specific technique of neutralization. However, the new techniques were discovered by reoccurring patterns based on their overall theme. Once a new technique was discovered, the data was re-examined to make sure there were no instances of it before it was located in the data. These new techniques of neutralization have some commonality with the traditional techniques but were different enough to classify their own categories or sub-categories.

Although useful, the forums also had data that was irrelevant to the research and was later discarded. When working with a large qualitative data set, Miles and Huberman suggest several 
data reduction techniques to make the data manageable. This research specifically used a 'presence of supporting conditions' matrix. In this technique, a matrix is laid out in which each corresponding grid is support for the column and row intersection. For instance, some of the girds in this research were both definitional and direct quotes from the forum that support the previous definition. These visual displays allowed for a quick analysis while not being bombarded with irrelevant information.

\section{USENET}

The original poster on an internet forum posts a question or a discussion topic to a specific site, in this case USENET, and others interested in the topic have the ability to reply at their own leisure. USENET is an online dataset that has archived various forum posts from around the internet. Forum posts can be useful sociological tool because they are "near contemporaneous accounts" rather than accounts have had to be remembered (Hopton 2007). Time can often shape memories so this data source is still true to its time. Repliers also have the ability to refine their thoughts while writing whereas in an interview they may forget to bring up important points that could later have an effect on the data.

USENET was created in 1979 as a medium for Unix network administrators to communicate and solve different problems (Delany 1995). After several years it moved away from just one topic to include thousands with just as many users. It is organized by hierarchy to include computers, miscellaneous, news, recreation, science, society, talk, and alternative which is unregulated (Delany 1995). All of these categories have several below them, as do the subset categories until there is a specific topic. A real strength of Usenet is that it builds off of our traditional 'turn taking' conversations. In real life people take turns speaking usually one at a time (Delany 1995). A thread on Usenet works in the same way by creating a digital conversation that reflects beliefs and attitudes just like in the traditional sense. Since people 
respond at their own leisure research shows that there is not as much "filler" in the conversations_-people are more likely to get to the point (Delany 1995).

Another strength of Usenet is that the anonymity of the internet makes it harder for people to utilize social roles and cues during their conversation (Delany 1995). It is hard to be a social actor when you do not know who you're even talking to. In this digital medium, the conversations on Usenet represent people's true opinions. They will not hold things back that social context or clues would have prevented them to say in a face to face conversation. It also allows for the merits of the argument to hold more weight. People respond based on the merits rather than the status of the poster (Delany 1995).

\section{Guardianship}

As this project conveys that guardianship plays a significant role in choosing a technique of neutralization, it is important to also realize the role of the guardian. A guardian is anything that is capable of deterring someone from committing a crime. Many popular guardians are police, store clerks, peers, and cameras. Many people don't also realize that things such as morals, virtue, and societal acceptance can also prove to be great at guardianship. However, for a guardian to be effective they must also elicit a negative response from the potential deviant or criminal. A guardian could catch people all day but if he gave them a sucker for committing the crime, it wouldn't mean anything. There must be some authority that dictates their ability to deter. A successful guardian deters because of punishment. This does not necessarily have to equate to physical jail time, it could also be guilt or anything else the person considers punishment. A great example would be the classic antidote where a child does something wrong and the parent aren't mad, they are just 'disappointed.' If the child wants to be accepted by the parents and do right by them this could act as a guardian even when they aren't with their parents. An effective guardian works because it has the ability to create any kind of negative 
consequence. That consequence depends on the nature of the guardian whether or not it's physical, virtual, or 'mental.'

\section{Coding the Traditional and New Techniques of Neutralization}

The data in the forum was coded differently, pending the neutralization used.

Reoccurring patterns resulted in the technique being included in the analysis. Rather than explain how each technique was coded and then further explain the traditional techniques and new categories, they are included later in the research. The only traditional techniques of neutralizations that were not cited in this analysis were a denial of victim and an appeal to higher loyalties. That is not to say that they are not used in other instances of piracy, it's just that these pirates did not cite these neutralizations.

Traditional techniques of neutralization have been useful at explaining many different crimes and internet piracy is no different. Throughout the forum posts there were several of the classical techniques of neutralizations used such as denial of injury, denial of victim, and condemning the condemners, however, some of the techniques of neutralizations used are slightly different than the five classical categories. This research suggests that in the realm of internet piracy—and perhaps even cybercrime in general -- there are several new types of neutralization used; Denial of Access, Lack of Humanization, Ambiguity of the law and an Out Dated System . These new types of neutralizations may share components with the classical versions of the Matza and Sykes original theory but also show several distinct differences. A new technique, denial of law, is also identified but is one of the weaker new technique of neutralization, despite protests from the posters.

Three of the five classical components of techniques of neutralizations were used, but not as often as the new found techniques. Out of the 216 forum posts denial of responsibility, 
condemn the condemners, and denial of injury were used modestly. The only two techniques that never appeared were an appeal to higher loyalties and denial of a victim.

\section{ANALYSIS \\ Traditional Techniques of Neutralization}

Denial of Injury

The first traditional technique of neutralization identified was a denial of injury. This technique was utilized when the there was a belief that since the item was copied, the artist and the record label were not harmed. An exaggeration of this technique would be to think only about the existence of one million illegally created copies. If these copies were to simply sit on a pirate's computer and never listened to, is that an injury to the artist? In this forum the resounding answer was no that does not create harm.

Denial of Injury was coded when there was no monetary loss for either the recording artist or record label. In denial of injury, the posters inherently understand that someone is claiming to be the victim but the overwhelming response is that no injury actually occurred. In essence, the person/organization could not actually be a victimized, because no injury was ever incurred. This neutralization was frequently invoked when forum participants argued or believed that the simple existence of an illegally duplicated copy did not qualify as harm to the artist or record label.

The posters point out that the author is clueless about a copy even being made making it difficult to argue that illegal duplications could harm the author. According to one poster,

The copyright holder is not materially worse off, he doesn't even know that a copy has been made. He would get $\$ 0$ if the copy hadn't been made, he gets $\$ 0$ if the copy was made. Net effect 
of making the copy on the copyright holder $\$ 0$.

According to this logic, a copy does not indicate harm. However, some posters took it a step further indicating that even if the music is listened to there is no way to predict if the person downloading and listening would have legally purchased it. According to another,

[The pirates] only know if they intended to buy it or not. If they didn't intend to buy it, but never had a copy of it (in the case of, e.g., Napster and a song) to use whenever they wish, that person can't know that they wouldn't have decided, later, that they just had to have a copy of this music.

These examples illustrate that whether they planned on purchasing the material or not, there is no injury to the author. This poster makes the point that there would have only been injury if the person would have bought the material, if they didn't pirate it which is something very difficult to show.

The central guardian for denial of injury is the feeling of guilt. This thesis is focused on the everyday, average, law-abiding citizen. This class of person usually does not which to harm anyone and there is a moral guilt linked to this behavior. When someone is injured, the 'normal' person would feel bad. This neutralization is usually effective because the person claiming injury establishes that real injury can occur. Just knowing this fact is enough to deter someone from committing the crime. If the pirate believes that the action of digital piracy does not create harm to either the label or the artist, then they will continue to pirate because the guardian has failed which leads to the use of this technique.

In cases of denial of injury the record label would rightly define the illegal duplications of music as harm to their business. The labels assume that if a copy is made it is one less that could have been purchased but there is no evidence that the people who have pirated something would have gone out and purchased it otherwise. The act of having and enjoying something that 
wasn't paid for would harm the copyright holder, if previously purchasing it was the only way to get it. A copyright allows the holder to control how copies are created and distributed and piracy clearly subverts this authority.

In this case, the guardian fails in convincing potential consumers of this harm thus eliminating any feelings of guilt. Despite the record label's protest that these actions inflict injury, their arguments are not substantial enough to deter piracy. There is not sufficient proof from the copyright holder that an unauthorized copy actually created injury, which eliminates potential feelings of guilt. In many cases, as pointed out by the previous example, they probably don't even know one has been made. Furthermore, they have not created a system that stops the illegal duplication; even things such as DRM have begun to fail. The guardianship lacks the essential capability of eliciting an action from the pirates. Until the labels are able to establish guilt, they are susceptible to this type of neutralization. According to one poster,

I say the existence of the copy is not harm because it does not in any way affect the market for additional authorized copies. The publisher makes not one less sale because someone copied a piece of music to keep somewhere else, rather than carrying the original copy to the other place.

If this person were to believe that the record labels had the exclusive privilege of determining the ability to duplicate, his stance would be decidedly different. This poster reiterates the point that a simple copy does not create injury because a simple copy does not mean any more or less work for the record labels.

\section{Condemn the Condemners}

The next technique of neutralization used was condemning the condemners. In this technique, the reason that people pirate is because the record labels are price gouging and it leaves no other choice for the pirate. They are not going to pay what they consider to be absurd 
prices, so they chose to pirate. Posters believe that record labels set the prices too high for the product that is available and attribute this inflation to wanting to only increase their profits. The retaliation of pirating, allows them to 'punish' the record labels in protest.

Condemn the condemners was coded anytime there was a reasoning used that blamed the record labels for their illegal piracy. Although it could have been coded with other guardians such as legislation, or record stores, pirates were quick to point the finger at the record label. When this technique was used it was almost always referring to the price at which the digital media was sold for in the retail environment. The price at which the record labels market the material was drastically different than the consumer's expected value. When these two dimensions were not the same, the pirate blamed the record label for falsely inflating prices to make a profit. Things such as market availability, the role of the retail store, and logistical costs did not factor into their use of this technique.

When posting on this subject many posters pointed to the price of the product as the reason they believe people pirate music to begin with. As one poster explained, most users justify it because the record companies gouge people with high-priced CDs that may contain one or two good songs with the rest fillers.

In this example, the poster claims that the high price of music is not justified because the songs on the CD are not as good as some others. They use the difference between perceived worth and market value to justify not paying for the item. It gives them the ability to claim innocence until the record labels offer the music for something they consider to be acceptable. One forum poster even takes it as far as claiming the reason that there is no public outcry against Napster is because of the high price of media. They stated,

the high cost of legitimate copies is the reason there's little public outcry against Napster. 
They clearly state that if prices were low enough for most people to want to purchase that it would be hard to use the price in a potential neutralization. If prices were reasonable people would more likely to attack Napster and pirates because they are subverting the system when the prices are low.

When the pirates are able to neutralize the record labels by condemning the condemners they have successfully shown that despite having the technical ability to tell them what to do, they have lost the ability to make them act. The respect they usually have is lost because of the discrepancies between the two parties, in this case the price point of the media. Companies charge a certain price that pirates believe is to simply exploit them. The normal 'law abiding citizen' would comply with companies or people in this position but they realize the disadvantage of the labels not being able to elicit a negative consequence. We have governments, teachers, police officers, and others that we must constantly obey or face the consequences, if we believe they have the power to enact them. In fact, obeying the 'person in charge' has become a societal norm. If someone goes against the grain and becomes a deviant or criminal, they receive punishments that most don't want. For many people, they religiously obey societal norms because that is how you remain accepted and avoid alienation. These things are important to the 'normal' person. In fact, they are so important that they act as a guardian to committing many crimes, and even digital piracy. In some cases, like condemning the condemner, these roles go out the window because of the ability to neutralize is based on unfair circumstances.

Obeying the guardian and complying by societal norms is not successful cases of digital piracy because the pirates believe that they are being wronged by the record labels and market. The record labels do not gain their respect as a formal guardian would and thus lose the ability to 
command the pirate into any kind of action, like legitimate purchases. They do not believe that labels are acting responsibly and are taking advantage of their position by price gouging the consumers. If the prices were lower, it would make it more difficult for pirates to use this type of neutralization. When the condemner is wronging them, they don't feel any need to listen to them and are not affected by the labels condemners' position. Condemning the condemner allows the deviant to avert social norms while simultaneously brining attention to how the record labels are abusing their monopolistic status.

The record labels create the price point and expect consumers to pay whatever amount is set and are upset when pirates subvert the system. Pirates would be unable to take this stance if the labels were more transparent with how they do business and came up with a collaborative solution rather than placing all of the blame on the pirates. When the price of the media is not what the pirate thinks is fair, it creates the mentality that the record labels are gouging their consumers on purpose.

When the consumer doesn't believe that the guardian has high enough authority to tell them what to do, they use that against them. They must believe that the guardian at play must be in a position to command them what to do. According to one post,

Do you really think that record company weasels would ever agree to give half the profits to the artists that created the work in the first place?

He specifically points out that the record labels want to see higher profit margins, even if it is at the cost of alienating their recording artist, which in return creates more distance between the consumer and record label. 


\section{Denial of Responsibility}

In denial of responsibility, Napster receives the blame for why digital piracy has become such an issue. The pirate takes the stance that they are simply using something that Napster has created. If anyone is to blame, it should be Napster. They are taking the blame away from themselves and placing it on to Napster. Napster has provided these services in such a way that there is no other use for their product except to download music. The pirates believe that Napster is at fault, not they.

This technique was coded when forum participants indicated that Napster should bear the responsibility for illegal downloading. It also included anytime that the forum participants believed that Napster did not fully disclose the purpose of their software. Participants who used denial of responsibility believed that the way Napster phrased certain claims on their webpage made it vague on what the program should be used to do. To illustrate their point, many of the forum participants would use a type of denial of responsibility to claim that Napster should have been more aware of the content going through the program and take appropriate action and since they didn't say it was 'okay' to download music from Napster. Although vastly outnumbered, there were a few instances of an argument that was made in Napster's defense but almost every time this technique was used was to misplace blame from the end-user to Napster citing their program is what allows piracy to begin with.

Napster does not specifically hold copyrighted material on their servers but it does provide a pathway to connect users to find what they are looking for. It is this service that has perpetuated digital piracy. It is true, however, that Napster could be used for legitimate, legal, means, but the logistics to ensure this are very difficult to put into place. Posters on the forum believe that since Napster is facilitating piracy because they know what the service could be used 
for and take no action to stop it. It is for this reason that Napster should accept responsibility for the digital piracy that occurs through the use of its service. One poster on the forum said,

Napster is generally -static- and is fully aware of its content at any given point. Since Napster is, or can be, aware of the content offered through it at any given moment, a measure of responsibility devolves upon it to control the content processed through it and prevent the abuses of copyright which are endemic to the system.

While this poster believes that Napster bares the responsibility of copyright infringement, another simply blames them for creating a program that enables illegal sharing of music. As they stated,

I think it is more accurate to say [Napster has] created a system that enables the illegal sharing of MP3s.

In cases of denial of responsibility, the question for law enforcement becomes, who should be prosecuted for these instances of digital piracy; Napster or the end-user? The pirates want to convince them that Napster has all of the responsibility because they are the ones facilitating the crime. Napster would rather them go after end users because they are offering a service that could be used legitimately but the end-users decide to abuse the system. Who is at fault makes a difference on how the guardianship determines the type of neutralization. If the law enforcement had already decided to pursue end-users, they would have had to utilize a different technique because claiming it was Napster that persuaded them to pirate would not be effective.

As a society we favor those who accept responsibility for their action, despite getting in trouble, those who accept responsibility also gain some respect for their efforts. For example, look at how some political scandals take place. There is denial from the political figure followed by an admission of guilt weeks later. Had the political figure just accepted responsibility, they would have 'gotten in trouble' but gained respect for being straight forward. In this case, the 
respect is not out weighing the potential outcome. Whoever gets the blame is also going to receive a giant lawsuit and no respect. In the case of denial of responsibility for digital piracy the law enforcement agencies are acting as the guardian and are unable to leverage gaining respect for either party because of the ongoing court case. The pirates don't believe they have to obey them because of their inherent belief that they bear no responsibility for what has happened.

Responsibility is important because not only does the person accept what they have done, it also gives us the ability to place blame. Generally when someone takes responsibility for their action there is an attached reward that makes it worth it. When criminals help police they sometimes receive a lighter sentence. When the benefits of accepting responsibility are outweighed by negative consequence the ability to use a denial of responsibility allows the deviant to justify their actions to the authority figure while simultaneously dissolving them of punishment.

In digital piracy the law enforcement agency is an unsuccessful guardian because is they are unable to punish anyone until the court case is completed and no one is sure who to prosecute and write cease and desist letters to. The pirates are free to act because punishment will not be enacted until due process has taken place. The record companies and legal system are incapable of having any effect on either party because of these limitations. Once the case came to a close, the authorities actually pursued both routes, punishing Napster and the end-user. Law enforcement was able to begin to punishing individual users and regain their authority over the industry. To do this, pirates were being sued for millions of dollars which helped control the decision of other people whether or not to pirate. Once law enforcement gained the ability to send letters and sue, they gained slightly more power but the sheer number of pirates limited their new found ability. 
Who should accept responsibility is something that was noted by the posters. One said,

For the first part; Napster is certainly guilty of copyright violation, the real issue is how much responsibility they share with the users who were actually providing the stolen content.

When it us unknown who should accept responsibility for piracy, they are able to hide behind this ambiguity. If they do not feel responsible for the downloading of illegal material, then there will be reason for them to stop. Many of these pirates felt that because of how Napster operates and stated claims on their website gave them the ability to pirate music while simultaneously denying responsibility on the basis that Napster was not clear on what the program was for.

\section{Traditional Techniques Not Used}

The two techniques of neutralizations that were not used were a denial of victim and an appeal to higher loyalties. Although they may be used in other instances, posters in this forum were not using them to explain digital piracy.

Denial of a victim was not recorded in the data but I did search for instances in which it could be coded. A running definition for a denial of victim was anytime the posters believed that their actions did not actually have an effect on anyone else. When speaking of a victim the people of the forum were quick to note how piracy would not have a great effect on the companies, but could potentially affect their favorite artists. This topic was debated throughout the forum but always came to same conclusion that there was a desire for their favorite artist to make some money, even if it's not very much. Denying a victim was difficult because of how much attention is given to the monetary effects of piracy and the artist who originally created it. Without buying the material the only way the artist would make money is through other means 
such as merchandise and touring. They recognized that pirating could be effective at disrupting the record labels but it came at the price of taking money away from the artist they wanted to support. They understood that the artist is part of the system but not at a high enough level to dictate the price of the material.

In cases that I suspected there would be a denial of victim, the posters were acutely aware of pirating had on the media business. Ironically, some of the posters pointed out the inconsistence of downloading when they are trying to support their favorite artist. Although they may not agree with the current system, it is the system that is in place and record sales do play a role in the payment of their favorite artist.

As one poster put it,

I agree the record and book distributors end up with most of the money but the only money the artist/author gets for his work is through these entities. If the distributors don't get money, neither does the artist. A system that reimburses the artist/author more equitably would be better but we don't have it. I don't like the idea of removing the source of income to the artist just because you don't like the distributor. You aren't hurting the distributor but you are certainly hurting the artist/author.

Clearly, some posters recognize that they could potentially harm their favorite artist.

Interestingly, when denial of injury was employed it was always used in the sense that there was no injury for anyone to even be a victim.

The other technique, an appeal to higher loyalties, was not specifically used to justify digital piracy by these posters on this forum. However, this technique is the basis for some of the other new techniques of neutralization. Though they do not specifically appeal to a higher loyalty, they simply appeal to a different loyalty.

When an appeal to higher loyalties is usually employed it neutralizes deviances by citing the action does more good than harm, or is for the general wellbeing of society. It was expected to not find any instances of this neutralization but some of the new techniques of neutralization 
share some commonality with this traditional technique. They don't necessarily appeal to a higher loyalty as much as they do a different loyalty. Many of the posters didn't pirate simply because they thought it was good for society but they were willing to give insight on what they would do to change the current system of digital distribution. The changes and reasoning they provide have created new techniques of neutralization that, with further research, could expand beyond not only this forum but to other types of cybercrime was well.

When speaking of a higher loyalty it is usually associated with something that would appeal to the greater good. The new techniques do not appeal to the greater good, just to a different way of doing things. The forum was filled of different systems that they believed would alleviate the problems technology has created when dealing with digital distribution. Some of the posters even predicted things such as iTunes, iPods, and more recently the Amazon Kindle. They predicted,

The idea is to get a system set up that is so convenient, widespread and cheap as to be an attractive alternative to piracy. I think that if a Napster-like system that contained absolutely every song anyone wanted to share was available legally and cheaply most people would use it

\section{New Techniques of Neutralization}

The purpose of this analysis is to see to what extent techniques of neutralization, as originally created by Sykes and Matza is applicable to the digital age and to what extent guardianship plays on neutralizations. This research question is analyzed by explaining the traditional techniques of neutralizations as well as new ones that were not accounted for when the theory was originally written.

The traditional techniques of neutralization were effective at explaining a variety of different crimes. All of them were used except two, denial of victim and an appeal to higher 
loyalties. As already mentioned, some of these new techniques are tweaked or combined versions of the traditional techniques. The differences between the new and traditional techniques are great enough that the following deserve their own category or subcategory.

Although they are all different these new techniques of neutralization share some commonality with each other. The first commonality is that they all deal with advancements in technology that did not exist when Sykes and Matza first created the theory of techniques of neutralization. Some of these neutralizations were not only impossible at the time, but they were also inconceivable. Not only were they impossible when the theory was written, they were also impossible when the laws were written. This unique advancement of technology has given us insight on how advancements in technology will change the way in which neutralizations are used.

The internet has played a large role in neutralizations but it has also brought to life several traditional neutralizations in ways that have not been previously seen. Not all of the categories may be totally new, such as Lack of Humanization, but they shed light on how technology is allowing for the evolution of Matza and Sykes traditional techniques of neutralization. The differentiation between a new category and technologically modified is noted throughout the following analysis.

The second commonality between the new techniques of neutralization is the role that the guardian plays on the internet. There are plenty of motivated offenders and suitable targets online so the deciding factor of crime becomes the guardian and how capable they are of deterring crime from occurring. Digital piracy, along with several other computer crimes, does not have the luxury of being observed easily. When sitting at a computer looking at the monitor there is nothing to mirror the physical situations in which a police officer, store employee, or 
security camera are watching. There is not even enough certainty that someone they associate with, such as an Internet Service Provider is monitoring their internet activity.

\section{Lack of Humanization}

Lack of humanization is not necessarily a new technique but an updated form of denial of injury. The way technology has advanced distribution has allowed for a new type of denial of injury to emerge while the classical version co-exists. In this technique, posters point specifically to the lack of commonality for the reasons that they are pirating. The corporations are not as easy for people to connect with or understand. When something is more relatable, you're more likely to act in favor of it. Recently, comedian Louis C.K. released an album without the help of record labels or any other corporation. While releasing his material he wrote a simple plea to pirates. $\mathrm{He}$ spoke about what was required for him to create this material and sell it for only $\$ 5$, an extremely low market price. He simply asked pirates to pay rather than illegally download his material because of the adverse effects of digital piracy to his livelihood. His plea was met with overwhelming support from not only his fans but the pirating community. This transparency creates a 'bond' between the two while a company isn't as transparent. People are more likely to understand something that is 'like them' than they are a large corporation, so pirates are more likely to steal when they don't understand exactly what they are stealing from. When they steal from a person they know the potential consequences whereas they do not understand the injury that occurs on a large corporation.

Lack of humanization was coded whenever there was any reference of the record labels as less than human or completely un-relatable to the pirate. It was also coded if the posters would refer to how they would rather give benefit to an artist rather than a corporation. When posting on the forum they were acutely aware of the artist and felt empathy for their potential monetary 
loss, while not thinking twice about harming a multi-billion dollar company. Any instances when these sentiments were reflected in the post were considered to be a lack of humanization.

This technique of neutralization looks at the actual record labels and their role in producing music. The record labels are usually extremely large and not personable to the average consumer. Simply, hippies of the 1960s could refer to them as "the man." They lack characteristics that the consumer can identify with. Consumers would prefer to deal with the artist directly rather than with 'money grabbing' record labels. They also believe that the goal of the record label is to do anything as long as it makes money, even if it's poor for the consumer. Despite their actual intentions, some consumers only see them as a middle man that only is in the game to make money and have no other effect on the music making process.

The first component of this neutralization is the belief that the role of the record label is no longer serves a useful purpose. As will be discussed when analyzing denial of access, technology has advanced to the point where the artist can directly reach their fans and consumers. It is free and simplistic to upload music and just as free and simplistic for other people to download it. One poster commented on why they believe the record labels actually oppose Napster,

they oppose Napster not because they are losing record sales (they aren't) but because it breaks their oligopoly on distribution.

Advancements of technology have changed the way in which we receive digital goods, which in return has a negative perception on the record labels. This person claims that the only reason the labels are going after Napster is because it is taking away power that they used to only have.

The second and more important aspect to this technique is the relate-ability of the consumer to the record label. When someone listens to their favorite musician they hear the 
music made by that person and there are no indications of what the record label has done. They understand that the record labels get most of the money for very little work and would rather see the money go to the actual artist. They have a hard time understanding why this faceless, unrelatable corporation should receive any of their money. As this poster put it,

I want artists to be able to make a living. I suspect that there is a relatively fixed amount of money people will spend on art (music, books, etc), and there's at least the possibility that new forms of distribution will get more of that money to artists and less to corporations.

There is a desire to pay the artist directly, but they refuse to give money to a middle man that is perceived to add no value to the work of art. Most clearly believe that the record labels are only there for monetary gain, while not really providing any services. One poster displayed his discontent,

the single most identifiable evil entity is very easily the blood-sucking pork-barrel record labels.

Like the other new techniques of neutralization, technology has played an important role in developing this neutralization. Once the internet created the ability for artist to cheaply, effectively, and easily communicate with their fans, the record labels became obsolete in the mind of the potential consumer. This evolution has allowed 'no name' artist to become famous because of the borderless and infinite structure of the internet. There is no longer are requirement to expensively produce 1 million records in order to reach the public. The only thing needed is a single copy that can be and perfectly copied a million more times. Once this ability is reached, the consumer does not see the role in the record label, they do not add any additional value to the musical product. 
Large corporations don't struggle with controlling consumers with physical guardians because they have no problem mounting the resources to create them and they have proven extremely effective. Things such as security guards, cameras, and electronic security devices are great deterrents of crime that don't exist in the virtual space. The problem that large corporations face in the virtual space is 'winning the minds and heart's' of the consumer. Consumers and society in general favor having something in common with the organizations. When Wal-Mart ventures into new markets there is usually an outcry from the local populous that they will destroy the 'mom and pop' stores on Main Street. Consumers prefer to deal with something that has a face and is recognizable to them. They would rather pay the artist directly rather than going through a multi-billion dollar corporation that is not perceived as having a major role. There are no personable attributes that connect the pirate and large corporation.

The record labels fail at guardianship because they lack the necessary characteristics required for pirates to feel any empathy. On the other hand, the actual artist make a great guardian because if their ability to relate with the pirates and for them to understand 'what they are going through.' For someone to feel bad for something they must believe that it has feelings too, some kind of sentient being. People will 'feel bad' for harming their friends, pets, or other living creatures. In this case, they would rather simply give the money to the artist and support them directly. This is partly due to the fact that some artists are able to demonstrate injury more effectively than multi-billion dollar corporations. Large corporations are not able to make a personable connection to the individual consumer. Having billions of dollars makes it difficult to relate with the regular consumer as well as deny injury. Although counter-intuitive, this was also seen when people were dealing with Metallica, the band who originally sued Napster. They believed that since they had so much money they didn't understand why people were not willing 
to pay $\$ 20$ for a CD that was not perceived to be worth that much. Metallica was worried about the millions of people that would spend $\$ 20$, while the consumer was worried where they could cut costs to spend $\$ 20$.

'Person-ability' can act as a powerful guardian but relies on the person trying to leverage it as a potential guardian. Labels are unsuccessful at this because of their inability to show relatable injury while artists are more successful. The labels have the ability to adjust market pricing, availability, and the income of the artist. However, their actions regarding piracy, namely suing their would-be-consumer digital pirates, has created an "us versus them" mentality that simply perpetuates piracy. When someone is sued for digital piracy the plaintiff is not the artist they love; it's the record label they already hate.

Until the record labels take action to advance their role in music production and either improves their public perception or ability to show injury, pirates will be able to neutralize some of the guardians they employ. The record labels are demonized because of their role in inflating the prices. When people listen to a CD and hear their favorite artist, that's all they hear. They don't hear what the record label actually did. To them, the label is nothing but a greedy middle man making money off their favorite artist. When this occurs the record label becomes the enemy and is not able to control their content. The media coverage that occurs when the RIAA sues a digital pirate does nothing but tarnish their already damaged reputation.

One poster on the forum took it a step further and put the blame on not only the record labels but also politicians because in the end they are the ones who in act laws and have the ability to play some role in these conversions. MP3s have been out long enough that responsible parties should be taking action rather than debating. 
The system needs to be changed. OK, lets come up with not just an idea of what a new system should be but ways that it could be implemented. We grone that we are sick of politicians saying they will do XYZ and not saying how it is going to be accomplished, well it's time to put up or shut up [in my opinion]. If we can present not just an idea but a method to legislators and keep pushing it maybe it will be possible to protect the rights of artists and authors and not stuff the pockets of the middlemen.

\section{Out-Dated System}

Out-dated system was the first new technique discovered when analyzing the data. This neutralization was created by the evolution from the physical format to a digital format. The outdated system technique is used when the person simply does not believe that copyright, in its current format, is a viable method to protect intellectual property. The entire system of distribution is completely outdated and is only limited to physical goods. They believe that digital materials are inherently different and should be treated as such, which includes advancements in copyright law. That is not to say they do not believe in the idea of copyright, they just don't believe in its current format.

This new classification is most closely related to the traditional techniques of an appeal to higher loyalties and condemning the condemners but has several distinct differences between these techniques. The pirates are not obeying the law because they think that the execution of the law should be done differently. If government officials and record labels were to change the way in which they enforce the law, pirates would be more likely to obey the law. It may seem like an appeal to higher loyalties based on technological advancements, but they are not exactly- higher loyalties, just different loyalties. The posters in the forum believe it should be done differently, they are not arguing that there is some underlying significance for the rest of society. Their opposition with the law lies within the governments responsibilities. The posters believe that if the government is not going to fix, worry, or do anything legitimate about piracy, then why 
should the pirates take it seriously? If this crime was that important, government officials would be debating a resolution and implementing laws that are technologically sufficient. There is a perception that government officials are not being innovative enough or taking the problem seriously, so it allows the neutralizer to question the severity of the crime. Perhaps if the government were taking the issue more seriously it would convey to the pirates the severity of the issue.

What helps makes this a new technique is that when they theory of neutralization was written, the internet and current technology did not exist. Prior to the invention of the internet, the market and consumer relationship was purely one dimensional. The consumer went to the store, bought something and left. The internet has introduced the digital medium in which the current, out dated, system could never have accounted for and has not caught up. In essence, the main difference is the new ability for something to be physical and digital at the same time.

As seen here, the poster comments on the differences between technology and copyright noting that reality has forced the hand of legislatures and if they wish for copyright to continue they need to update the system. According to one,

The reality is that people are now technologically able to copy, almost free of charge, anything they want to. If copyright as a concept is to survive at all it has to adapt to that reality.

Once something goes digital the resources needed to make an illegal copy are drastically decreased. A digital item can be easily manipulated, copied, and traded with literally no change in sound quality. The realization that copyright is failing in the digital age was all across the forums. It was a point that many of the posters agreed with, as another person put it, paradigms and business models will have to be found and implemented. 
The current system of physical guardianship involves both physical and moral guardians which were established long ago. The role of police officers and the law are completely understood which help establish our own personal moral code. For example, laws and morals in China are drastically different than here in the United States. The guardian's ability to create negative consequences is essential to deterring crime. Even if people in the physical space don't agree with a law most are not devoted enough to risk negative consequences, such as prison, for disobedience.

Active guardians in virtual space that specifically monitor for deviant behavior do not exist as they do in the physical space. The current system of copyright and many of its attributes do not translate well. The differences between physical and virtual copyright are so great that the differences in technology has created the need for a new system. The logistical issues with applying traditional copyright laws in a new technology are far too great. The internet is global so one country's laws are not recognized in another. There are also far more people using the internet than are available to monitor them. The guardians in this case fail because they are not translated very well into the virtual space. Whereas in the physical space deviants understand the guardian has the ability to make them do something that isn't so in the virtual space. The guardians have not evolved at the same rate at which the crime has. If active monitoring guardians fail the labels, law enforcement, and legislators must create a new monitoring system rather than try to 'fit a square peg in a round hole.' The guardians in place have been unsuccessful at convincing deviants not do something because they will get caught, but because it is wrong and this is key to their success online. Unlike the physical space the virtual space also does not have the tradition of norms and obedience. 
In these cases of an out-dated system the guardians are operating in a way that is inconsistent with the current method of distribution. Law enforcement is arresting people who think they are progressive and are currently doing the right thing. While technology is moving forward, legislators are not creating and enabling guardians that are successful in a digital age. Rather than updating and improving the system, they keep one in place that is no longer effective and simply try to prosecute and arrest everyone who breaks the law. Legislators must realize the effectiveness of the out-dated system neutralization in order to create a moral guardian that has the ability to command and elicit action from the deviants. In cases where they cannot always be watching, potential pirates need something besides traditional, active guardians to guide their digital behavior. Even though most people in the physical space don't steal because of their 'moral code,' this hasn't been the case in the virtual space.

Although all of the guardians in place are attempting to deter crime, they are not working. Technology has made it easier to copy music from a physical to physical format, physical to digital, or any other combination. Once it became this easy and the technology for Napster was available there were so many people doing it and not enough resources to stop piracy. A good analogy would be to think about an exaggerated scenario involving drivers speeding on the interstate. If the speed limit where the officer is watching is 50 miles-per-hour and literally every car passing is doing 100MPH there is clearly no way the officer will be able to ticket them all. They may catch some, but a majority of people will get away with it. Until the current copyright system changes, there will be a lot of people speeding. Rather than waste time attempting to punish the few of many, legislators and law enforcement should spend their resources more wisely by creating innovative solutions to a wide spread phenomena. 
In the end, many of the posters believed that Napster had single handedly changed the system in which copyright will exist. Technology has created a system in which many believe that information should be free and that the digital age should not be limited by laws reserved for the physical space. Many posters even realize that copyright is something we created as a society and is not inherently 'bad,' it has just been defined in such a way. As one poster put it,

Napster is the symptom of a wave of change. Copyright will be a casualty whether napster lives or dies. (Don't forget, Copyright is an artificial construct of the 20th century.) It is simply toooo easy to propagate copies (that are copyrighted by current laws) of any work in today's world of open-source, share the knowledge underbelly that is the internet.

\section{Denial of Access}

The second new type of neutralization was Denial of Access. This technique has also evolved has technology has created new and unique situations. This was coded when they referred to any kind of obstacle that blocks them from legitimately listening to the music. There were instances of out-of-print material, distance, and technological barriers that were all included in this technique of neutralization.

In this technique the pirate has no other legitimate means to access the material. If they want the music, the only way they would gain access is through illegal piracy. Had the music been legally available they would have went through legal channels to obtain it, but since it was not they resort to piracy as a last resort. In this technique the particulars of why there was no legitimate access are of no concern, whether it is because it's not in their local stores, it's out of print, or the closest copy is hundreds of miles away.

Denial of access is one of the most compelling new techniques of neutralization. The neutralization is so effective for some that it completely negates any illegal behavior. When people try to do the right thing and then are forced in to a situation where the only way to get something is to do something illegal, it is sometimes not looked at in the same way as other 
crimes. This technique makes sense because they convey how much of a legal, law abiding citizen they are before deciding to pirate. They tried to be legitimate and the companies failed to provide certain services in which they had to take matters into their own hands. Denial of access resembles condemn the condemners but there was no initial, intentional harm. This new technique just highlights how technology has advanced past our current understanding of techniques of neutralization. It's not hard to imagine that if record labels knew that their products would be pirated on the scale that they have, that they would have created a better digital distribution system. It also resembles a denial of responsibility because the pirates are claiming they would have done it differently if the labels would have let them. It is only different because it is not something 'out of their control.' They had the opportunity to get it differently but decided those means of acquisition were too much work. It is hard to make the claim of denial of responsibility when they have the ability to get it, but just don't want to do it. Another difference is that piracy is not something you are forced to do. They could have simply not purchased it, waited, or found other legal means to get ahold of the media, nothing negative would have really happened had they not gotten a certain song or CD to listen to.

When the good is not easily accessible people will begin to look elsewhere for it and maybe even commit a crime they wouldn't normally commit. Here, one poster describes his decision to use Napster to find music that is out of print,

My personal ethics don't require me to not use Napster, as long as I don't use it to download and keep copyrighted material available elsewhere. I mostly have no use for what passes for popular music these days, but would like to find some long out-of-print works and forgotten (except by me and a rare few others) artists. Some of these are starting to come back into print and I buy them when I can. 
Even when discussing artists that are currently in print, some posters acknowledged that the internet and Napster provide a more extensive music collection than their local record stores. If it isn't in the stores and online retailers were not yet present, it makes it difficult to legitimately gain access and thus lead to piracy. They stated,

There are many songs that can't be bought anywhere [but are] available from Napster. No record store could match the diversity Napster offers.

Before online retailers were as popular as they are today, the only way to get an item was if it was physically at a local retailer. This may be hard to image in today's iWorld, but plays a drastic role in why this technique was never seen when Matza and Sykes wrote the original theory of neutralization. The ability for goods to be both digital and physical is something that was not present when the theory was written. Technology has also destroyed physical boundaries that could prevent people from getting material. It was inconceivable that something that was not still being produced--would still be available. It was also not feasible to travel to hundreds or thousands of miles away to get a $\$ 10 \mathrm{CD}$. Technology has created a new system in which the physical copy may vanish but still exist exclusively on the internet and be available anywhere in the world.

When a physical copy of media is not available for purchase anymore that it is not the same as completely ceasing to exist. Record labels and movie companies are notorious for 'limited editions' and 'special printings' of select items. They also have the ability to stop printing or producing material at anytime making it extremely difficult to obtain rare items. When this happens the record labels have not, during the era of Napster, given consumers another option than pirate if they are looking for out of production or goods. Even though technology has changed the industry and market availability authority figures are maintaining an 
enforcement method that only recognizes a legally produced physical copy, in instances of nonproduction, as legal.

Denial of access relies on the traditional consumer and manufacture relationship. People shop at stores and retailers because they provide a good or service that otherwise could not be provided. For example, we buy Florida oranges in winter because otherwise, local temperatures in January do not promote their growth. Other things we cannot do ourselves, like molting metal and other materials into computer chips that build our laptops and computers. They are in business because they do things that the 'normal' person cannot do, and many times they are the sole recourse for that good or material. In this case, when that 'contract' is broken pirates believe that record labels have lost their authority to 'command them to do something.' The guardians that are usually at work in retail interactions that prevent stealing are no longer effective. They lose legitimacy because they are no longer holding up their end of the traditional way of business.

The manufactures or record labels in cases of denial of access have and are not providing a legitimate mean to access a specific type of good which gives an opening for digital pirates to neutralize. The record labels should be able to deter crime, but when their ability to command and punish is lost because of inadequacies, this neutralization occurs. Pirates during the Napster era may not have pirated if they would have had easy legitimate access to certain digital music files. Legitimate accessibility is a guardian to many different types of theft. If a song was no longer available in the physical space but could be pirated, this played into the decision to pirate. However, this is usually the second option because people will use legitimate channels if accessible. When the company is not providing a good as it should, there are no longer any guilt 
or morality issues with circumventing the system. Their belief is that they already tried to do the right thing. They are in the moral clear because of this.

In a digital age this mentality is what is creating tension between retailers and consumers. The logistical limits created by our physical space such as distance, time, and money do not necessarily exist in cyber space. You may not be able physically go to a retail store 500 miles away, but you are able to sit in the comfort of your computer chair and access computers on the other side of the planet in less than a second. When this is considered, the internet becomes limitless with possibilities of obtaining material that is no longer in production. If someone else, anywhere in the world, has uploaded it only once it becomes accessible for all, no matter the location. Things are no longer 'out of print.' The MP3 has advanced the way music is sold but retailers had not caught up. It was not until iTunes and Amazon was there an almost unlimited selection of music.

This failure in guardianship is easier to notice when looking at how consumers perceive the record labels role in music distribution. Before the internet it would be a logistical nightmare for an up and coming artist to successfully market themselves across the United States, let alone ship enough CDs to make a profit but now that the internet has essentially erased these logistical issues, artists have the ability to reach their fans directly. The MP3 has made it so only one copy must be uploaded rather than printing thousands of CDs. As one poster put it, the "MP3 got established before the recording industry caught on. And now they are faced with a technology that can let artists ignore them and sell directly." When looking at denial of access the same principle applies whether it is artist to consumer or consumer to consumer, they are able to bypass the current system guardianship to transfer the music and adequately neutralize if they need to. 


\section{Ambiguity of the Law}

The final new technique of neutralization lies in an interesting area that has been created since technology has advanced. For many people their socialization has taught them very basic laws, not only because they are illegal but that they are 'wrong'. Children are taught what theft is at a very young age and this carries through their entire life but these types of physical definitions do not transfer very well to the internet. The ambiguity of the law neutralization is used when a pirate points to the inherent differences between physical and digital goods for the reason that they pirate.

When the people posting in this forum talked about the inherent differences that exist when speaking of theft of a physical good versus the theft of a virtual good, this was coded as ambiguity of the law. Most of these discussions talk about the different properties of physical and virtual goods and if they fit the traditional definition of 'theft.' This neutralization was successful because the posters who used it claimed they had not actually stolen anything, and therefore their act of piracy was okay.

The key to ambiguity of the law as a neutralization is the exact definition of the crimes being committed. Although they are both illegal, the perceived severity plays a key role. When neutralizers use this they look to the specific definition of theft vs. copyright. Theft is taking something from someone else to the extent that it deprives the original owner the benefit of its use. On the other hand, copyright is the idea that only one entity has the legal ability to make duplications of a specific item. If the pirates merely copy an item, they are not depriving anything from the original owner. Specifically, they haven't stolen anything; they are simply enjoying an exact duplication. In their minds, no crime has really been committed because they 
haven't stolen anything; they just created a new copy. They hinge their defense solely on physical and digital differences, just because its digital it should be treated differently. The posters argue that they are in fact obeying the law. They haven't broken it because what they are doing is not theft because it isn't defined as so. The law has not caught up with technology so they are in a gray, lawless area. The government assumes that physical laws carry over until digital specific ones are made, if they ever are. These neutralizers are taking advantage of that assumption.

As sociologist and criminologist definitions are important for a myriad of reasons. In many cases they help us define what a norm is so that society understands what they can and cannot do in normal circumstances. Adversely, we also use them to define differences between deviant and criminal behavior. This new neutralization takes this notion to the extreme. Although pirates are technically breaking the law, definitions haven't caught up with their way of thinking. To the 'average' person theft is clearly a crime; if you steal something, you are a criminal. The way digital piracy has been tackled has left this up to interpretation in the digital arena. Pirates believe that since something has been taken, it has only been copied; their action is deviant at best. This new neutralization leverages these differences to distinguish why pirates are not actually committing crimes.

As stated, a working definition of theft would be that you take something from someone and completely deprive them of it. On the internet things aren't so cut and dry. One poster commented,

Copyright violations lack the essential characteristic necessary to be theft by most people's definition. 
Since the item is digital it technically hasn't been deprived of anyone, it has simply been copied so other people have access to the item simultaneously. It is hard to steal something when everyone still has access to it. Like another poster said,

Physical property is limited. One person can't use it while another person is also using it. Not so with IP.

The differences between the physical and digital item, combined with traditional definitions of theft create the illusion that they are not actually committing a crime.

Technology and digital items have produced this ability since the original theory was written. It was not possible to instantaneously make identical copies. The differences between physical and virtual goods create a new area in which there is not a direct comparison allowing people to define this 'new' action as legal. They know that it is not stealing and so do not feel the same as if they would have stolen it from a store. The physicality of an item plays a role in to what people traditionally believe theft to be.

In ambiguity of the law, the knowledge that something is illegal comes into play and is key to guardianship. Laws are usually well defined and specific enough that the average person is able to follow them. Even without the presence of physical guardians, the fear of breaking the law is what stops someone from doing it and usually acts as a great guardian. Many people refuse to smoke marijuana just because it is illegal. The presence of an active guardian, like police, is not required for most people to not commit crime; the knowledge that something is illegal is enough to deter.

Despite law enforcement and the record labels intentions, the public do not perceive theft and copyright violation as the same thing. This definitional dilemma creates a difference between what they want done and what the pirates consider being legal. Law enforcement's 
ability to clearly command the potential pirate is in jeopardy because of these definitional differences. If they are unclear about their intentions or even if the meaning is 'lost in translation' the pirates are able to neutralize off of this guardianship quality. The law loses its capacity to punish when it's not completely understood. The pirates do not believe the current copyright laws classify as deviant behavior. The guardian does not serve the purpose in which it was intended because it has not been clearly defined.

When looking at guardians in the physical space they are anything that can deter crime from occurring whether it is a person or security feature. One of the problems with the internet is that these active types of guardians don't really exist in a meaningful matter in the cyberspace. When a pirate goes to a web service such as Napster, there is no equivalent of a police officer standing there watching them, the internet instead relies on passive guardians such as the law to deter crime. Because of the laws inability to act as a guardian online and active guardianship is difficult online digital crimes such as piracy flourish. Active guardians that are based on being watched, fail on the internet because they do not have a large enough presence to deter crime from occurring. It would take a presence strong enough that the potential pirate knew with some certainty that there is a chance that they could be caught. If law enforcement agencies are unsuccessful at clearly defining the differences between copyright infringement and theft and thus enhance passive guardianship, they will need to create a new system of active guardianship on the internet that deters crime in a similar fashion as the physical space.

Regardless of format, copyright is something that has been a tricky issue to tackle. The increasingly popular digital format is changing the law quicker than legislators can adapt. However, the physical format is not ceasing to exist, so traditional laws still have some functional application. It is hard to create and enforce two separate laws on the same issue and 
have success. The success of the MP3 will dictate how to move forward with copyright

legislation. One poster noted these differences between the 'real' and virtual worlds,

Moreover, there can be only one code of conduct for a society with one legal class. Saying that laws applying to the Real World do not apply to the Virtual World creates two classes of individuals, those who are on-line (who have one set of rights and privileges) and those who aren't (who have a different set).

\section{Denial of Law}

Although pirates attempt to utilize this new 'neutralization,' it does not appear to be the most effective technique discovered. If neutralizations are not grounded in some kind of notion that negates the criminality of their action, they will have a harder time convincing others of their justification. In cases of denial of law, the posters attempt to negate their actions by pointing to a disbelief in the law. They fail at successfully neutralizing the behavior because they essentially say 'yes I did it' without any kind of defense. When the posters attempted to utilize this technique they admitted their crime and merely gave an account of why they did so. This neutralization was included because it seems as if the pirates believe that they are effectively getting their point across while they are simply only giving an account of why they committed digital piracy.

Denial of law is a total disbelief in copyright regardless of the medium, physical or digital. Since the pirates do not believe in the law, they do not follow it. When this technique was attempted it did not matter the medium of the good, they simply didn't believe in copyright and pirated the material regardless of it was illegal or not. There were often comparisons to prohibition when this technique was used, and these analogies were also coded as a denial of law. Whether it be a misunderstanding or total disbelief, they didn't follow it because they didn't feel compelled to. They believed this law had no ability to tell them what to do and clearly was 
not substantial enough to make them act. They believe that the wide spread disbelief of a law is enough to absolve them of all their crimes. As mothers around the world have always said, just because your friends are doing it doesn't mean you need to. It should be noted that this is different than the out-dated system technique because that technique is based on the idea that copyright needs to be updated while this technique is based on the idea of abandoning it completely.

The aim of this technique is to appear larger than the issue of digital piracy itself, much like an appeal to higher loyalties but they never identify any real reason of denying the law and not believing in something is hardly a loyalty. It attempts to speak to the obedience of a law by the total population. It is true that it becomes difficult to enforce a law in which society no longer believes in but that fact alone does not help neutralize behavior. This argument is frequently used in victimless crimes such as smoking marijuana and drinking alcohol. One poster was quick to point out the similarities between prohibition and this issue,

Think Prohibition. When too high a percentage of the population is freely violating a law it is no longer a viable law. Estimates from RIAA are that Napster will have 70 million users by the end of the trial. We're going to need more prisons.

Violating an unpopular law stops carrying the 'weight' of violating 'normal' laws but a lot of people violating the law does not demonstrate a sufficient technique of neutralization. They are only admitting they broke the law just because other people are. Another poster tried a similar defense,

Ultimately, copyright law relies on the public accepting it A final poster shows that a lot of digital pirates are not concerned with the law. As they don't believe in it, they are more worried about simply getting away with it. The poster stated, "the 
laws aren't seen to be basically fair then the question for many people is not "is this illegal" but "can I get away with it."”

Although this neutralization may not work as well as others, they are still bringing up valid points on how authorities must execute an unpopular law. In the end, copyright and all other laws face the same dilemma; the public has to accept and abide by the law regardless of popularity. Resources will eventually play a role in the debate in that police departments only have so many resources and how much of them should be dedicated to a law that no one follows, you can't arrest everyone. Their tactic may eventually work but in the meantime an account of disobedience is not an actual neutralization.

Techniques of neutralization are used by criminals because in their mind they have completely justified the behavior as something non-deviant. In this technique, they admit to the commission of crime but are not successful in conveying that just because other people agree that their action is no longer a crime. Moreover, this thought is so popular that the pirates believe that once disobedience reaches a critical mass the law loses its power, thus dissolving them of any previous responsibility of pirating. They recognize that everyone is committing the crime and attempt to hide behind the sheer numbers and the "everyone else is doing it" excuse.

When laws are written they are usually meant to provide for the greater good. People may not always like them but they understand things like the seat belt laws were introduced to save people's lives. There is a distinct difference between not agreeing and not believing in the current laws. When you disagree, there is at least an appreciation for the bigger picture and still obey the law while disbelief occurs because they don't see any part of the law as benefiting society and thus do not follow it. Denial of law neutralizers don't believe in the loyalties of the 
current establishment but do not offer suggestions as to what they could classify as a higher loyalty.

Legal scholar Roscoe Pound once spoke about the need for sociological jurisprudence in 1907. Despite being written over 100 years ago, his theory helps explain why the denial of law is attempted as neutralization for crime. Government and law were created out of necessity to ensure a peaceful society (Pound 1907). Now, society plays a large role in government and the creating of different laws. Despite this notion, governments still create law without the notion that society is playing a major role, they make laws that look great on paper but don't always work in action. He notes that when large numbers of individuals are disobeying a certain law, that it is the government's role to reexamine the issue and create laws based on social interest (Pound 1907). Just from the severity of piracy, legislators should reexamine digital piracy laws to at least improve guardianship to the point of total effectiveness.

The desire to be a lawful citizen is based around the premise that society believes that the laws are serving a purpose. In the case of copyright law, many of the posters believed that the law is an outdated tradition that is no longer serving its purpose. The internet and digital reproduction have only expounded the disrespect of copyright law as currently written.

In cases of denial of law, the guardian of simply obeying the law is unsuccessful. Many people, especially 'average law abiding citizens' do not want to break the law. They realize the purpose it serves and they also realize the consequences that can occur if they break it. When these neutralizers are trying to use this neutralization, they are using this same type of logic. In order for this neutralization to be effective they would have to provide more reason of why the person committed the crime other than "because I can." Neutralizations are effective because they attempt to show that the action that occurred wasn't really a crime, was out of their control, 
or anything that 'justifies' their actions. Denial of law neutralizers are not as successful justifying their actions as some of the other techniques identified. In many cases, they are just giving an account of what happened with little further insight. They appear to be criticizing the authority of the law with their new technique but fail to do so in a meaningful way. Interestingly, they believe that this neutralization is effective and thus rely on it to defend their actions.

\section{LIMITATIONS AND FUTURE RESEARCH}

There are several limitations to this research. This research only takes into account the forum postings of a small group of individuals. Although there is no logical reason to suggest that their pirating habits are any different from any other person, it may still be a possibility. This research could not get any clarification on why certain things were said, where as another method may have been able to elicit more detail. A final limitation of this project is that there is no demographic information that could help explain why some of these techniques were more popular than others. Despite giving insight to new techniques of neutralization these items are for the era of Napster and only provide a direction for future research in an era that trades Napster for BitTorrents.

This research is limited to a small group of people and thus the results cannot be extrapolated to a larger population. Future research in this specific area, digital piracy, could be used to perform a survey in which these specific techniques of neutralizations are tested for statistical significance. This research used Napster as a case study because it was the landmark narrative, but as mentioned several times digital retail services were not yet created. Their availability could be a role in the techniques of neutralizations used today. If they are largely 
applicable to digital piracy, the field could also be benefited of an analysis of these techniques in relation to not only other technological crimes but also traditional ones as well.

Future researchers should also be interested in testing 'traditional' sociological theories against our modern technology. In this age technology dominates almost every aspect of our lives and that includes social interactions. These theories should be tested as to not one day become completely obsolete. As this research shows, these results cannot only support previous theories but also expand on them to include conditions that could have never been covered when they were written.

Although not specifically related to this particular research, other researchers should be interested in taking a similar approach as this thesis. Many sociological theories were written well before the internet and modern technology and therefore must be tested against these mediums to see if they are still viable in the technological age. As technology advances we are spending more and more time on the internet and interacting with different people. The internet is a unique location that traditional sociological theories are unable to take into account.

\section{DISCUSSION}

This research has shown that not only do traditional techniques of neutralization apply to the digital age but that technology has helped create several new categories. In addition, this research has also shown that guardianship matters when selecting an appropriate technique of neutralization. This qualitative analysis supports the initial research question and provides insight to both how technology has affected techniques of neutralization and routine activities theory, especially concerning guardianship.

The traditional techniques of neutralization were applied much like Matza and Sykes had originally intended them to. It is impressive that most of their categories of neutralizations are 
still as effective to today in explaining crime as they were then. As interesting as these results were, it is more interesting that technology has created a new system of techniques that were not applicable when the theory was originally written. These new and updated techniques all hinge off of technology and the differences between the internet and the physical space, especially when discussing the role of guardianship with neutralizing deviant behavior. Each one of the new techniques gives an important contribution as to why digital piracy was occurring when Napster was popular.

In an out-dated-system technique there is a total disconnect between what the person neutralizing believes should be done and what the government is actually doing. If there are going to be successful copyright laws, the consumer needs to believe that something is actually being accomplished and restore the guardian's ability to control a person's actions. This technique shows us the importance of an educated legislator because the current guardian's at play are not advanced enough to deter piracy. When the pirates realize that the current system is out of date and no one is really doing anything about it they will not have problems using this in their neutralizations. When this neutralization is used it allows the pirate to believe that they are not doing anything wrong because the actors involved have not advanced enough to understand what they should be doing. The pirates are able to take solace in the fact that when digital distribution is controlled and regulated; they were doing what they should have been the entire time. Their belief in how ineffective the system is, combined with their assumption that the authority will catch up to their mind set allows them to pirate without any type of guilt.

In the next new neutralization, denial of access, we see that technology has played a significant role in the distribution of media. The ability for something to be out-of-print completely is gone forever. Once something is digital it will continue to exist into eternity, 
especially when enough people have access to it. However, this technique extends beyond the simple availability of the item. Even if there are other things blocking legitimate access such as money or distance, this could still lead to piracy. It was not until after Napster settled their case that iTunes was created. This neutralization is effective because the person really believes that their reasoning for pirating is legitimate. They start out with good intentions but all of the legitimate means to access are completely blocked. Active guardians such as a store clerk or security camera may stop them from stealing the item from a physical location but the internet does not afford these same protections. When they visit Napster or a similar $\mathrm{p} 2 \mathrm{p}$ networking site there is no indication that anyone is watching. This total lack of visibly identifiable guardians leads people to commit a crime that they normally would not commit at all. In fact, this may be the reason that most of the crime on the internet occurs is because they believe that no one is watching them. If there is a complete failure in instilling passive guardians, such as morals, record labels will have to find a way to create a visible guardian on the internet that could lower crime levels to something similar to the physical space.

The third neutralization was an update to denial of injury. In a lack of humanization the key strength of the neutralization is exploiting the guardian's inability to relate to the consumer thus voiding its claim to injury. Large corporations have existed long before the internet allowed people to trade music illegally, so it may seem surprising that users are just now utilizing this neutralization. A lack of humanization is effective because the end user is now able to directly connect with the artist themselves. Prior to the internet it would be difficult for an artist to get off the ground without the assistance of a major record label, but now the internet allows instant communication, making social communication more personable. Having a single identifiable person creates a situation in which they know who they are hurting and perhaps more 
importantly who will not be harmed. A good analogy on why this may occur is to think about taxes. Clearly there are people opposed to paying any kind of tax to the government. If they were to take the tax money they are paying to the government and give it directly to the person it benefited, they may be more likely to pay it, especially if they saw firsthand the impact of their money. Giving money to a real person is different than the government taking money out of their paycheck every two weeks. The same principal is true in digital piracy; they would rather give the money directly to the artist rather than going through the record label.

The final neutralization, ambiguity of the law, is an important new technique of neutralization because it showcases the differences between virtual and tangible material. Traditionally theft is taking something from someone and depriving them from using it again. Digital items have allowed us to take something while allowing both parties to have access to it simultaneously. This ambiguity is what allowed the people on the forum to use this technique. It did not fit the traditional definition of theft and therefore is not theft.

The denial of law technique is important because it gives insight on how neutralizations may not work as intended. If a law is created that a large portion of the population disagrees we now understand that they will attempt to use this as a neutralization but they are successful in pointing out it would be near impossible to arrest everyone who has downloaded music illegally. Even though this is a valid point it does not neutralize their behavior as much as it gives an account of why they did something. The similarities to prohibition were pointed out by several posters as if it were supporting evidence for their cause. Even in the physical space the people that were using this technique believed that copyright will never be able to work after the creation of the digital media. An out-dated-system neutralization would call for an overhaul of the copyright system, while a denial of law neutralization calls for entire law other than 
copyright. They maintain that a law should only be law while it is still serving its purpose and the copyright law has many flaws that could be improved by writing a completely different law rather than trying to patch the current ones.

The information received from these techniques of neutralization strongly implies that visible guardianship plays an important role in deterring crime. One of the main reasons that guardianship has failed online is because passive forms of guardianship have not been created in a meaningful way. Although this may seem obvious in the physical space, it is something that does not translate to the internet. As I already stated, there are plenty of people monitoring the internet, they just aren't able to see what everyone is doing at all times. It is like a panoptic prison in which there are trillions of cells and ten guards looking for illegal behavior. It is something that the pirates know and exploit. Because of the global nature of the internet and the inability for active guardianship to truly work, law enforcement and legislators should try to utilize campaigns that educate the public and instill a passive guardianship that deters crime. They need to convince people to do something because it's wrong regardless of whether or not they will get caught.

If policies in ending digital piracy are to be effective, they would be wise to take these techniques of neutralization as well as their effects on guardianship into account. If policy makers know these neutralizations they could craft policies around them. For example, certain and swift punishment, much like in the physical space, would go a long way in slowing piracy rates. If there is a sophisticated monitoring system in place, a comprehensive passive guardian, or a combination of both, people may be more likely to avoid piracy. 


\section{Connecting Guardianship to Neutralization}

All of these techniques show that the guardian plays an important role on which technique of neutralization is used. Depending on what actions the guardian is taking, dictates what the neutralization the pirate will use. The importance of the interaction between techniques of neutralization and capable guardians extends beyond digital piracy. Guardians could use this information to become more 'capable.' Routine activities theory assumes that because there is a guardian that inherently makes them capable. On the internet we can see that this is not the case. There are plenty of agencies that monitor internet traffic, but none of them are able to stop internet piracy from occurring.

Routine activities theory suggests that crime occurs when there is an absence of capable guardians. At all times there is more than one guardian that should determine whether or not a crime is actually committed. For piracy, this research exams guardians that range from the record labels, morals, the law, to the actual artist, but there are plenty of different potential guardians that the pirates never mentioned or attempted neutralizations for. It is important to realize that just because many guardians are established that doesn't necessarily mean they will all be capable of deterring crime. It is not the number of guardians that matter, but the quality of guardian that leads to capability. How capable a guardian is, is something that the potential deviant decides for him/herself. Guardianship must meet certain qualities to be considered capable and deter crime; if these qualities are not met then the ability to neutralize is created based on these shortcomings. For many the law is guardian enough, while others consider active guardianship more capable. Guardians are what help deter crime despite potential motivations for doing it. It is possible for someone to blindly follow the leader or do something for love but in the end, that speaks to how the guardians that would have deterred crime have lost their 
authority. Out of all of the potential guardians they could have neutralized, the pirates strategically chose certain guardians to neutralize their behavior. Understanding the properties of guardianship will give way to a new understanding of what exactly comprises a capable guardian.

Despite the differences among the traditional techniques and the new ones identified in this research, they all share specific connections to guardianship qualities. Particularly, neutralizers are able to point to the total effectiveness of the guardian to give credence to their neutralization. Two aspects of guardianship that help regulate neutralization are authority and capacity. Authority is the ability to command someone to do something. In other words, they are in a formal position that gives them the power to command instruction to a potential deviant. On the other hand, capacity is the ability to elicit a certain action. Capacity relies on the ability to establish a negative consequence. Things such as feelings have, arrests, stigmas, ridicule, and even disappointment can act as powerful deterrents of crime. It should be noted, that a command does not need to be given to get someone to do something.

Authority and capacity can vary in strength which gives insight on the capability of the guardian and thus the necessity of neutralization. The four different combinations of these guardianship qualities would be High Capacity and Low Authority, High Capacity and High Authority, Low Capacity and High Authority, and Low Capacity and Low Authority. These four typologies are exemplified by guardians pointed to in several different techniques of neutralizations presented in this research. 


\begin{tabular}{|l|l|l|}
\cline { 2 - 3 } \multicolumn{1}{c|}{} & High Authority & Low Authority \\
\hline $\begin{array}{l}\text { High } \\
\text { Capacity }\end{array}$ & $\begin{array}{l}\text { The law (Physical } \\
\text { Space) }\end{array}$ & Peers (Informal Sanctions) \\
\hline $\begin{array}{l}\text { Low } \\
\text { Capacity }\end{array}$ & $\begin{array}{l}\text { The law (Virtual } \\
\text { Space) }\end{array}$ & Licensing Agreements \\
\hline
\end{tabular}

The first group of guardian characteristics, high capacity and low authority, was not specifically found during this research project but conceptually exists. It is a type of guardian provided for in routine activities theory. Routine activities theory states that informal guardianship if effective which could be something like ridicule from peers. Although peers do not 'command' they are able to make someone act. If the ridicule is not a sufficient enough reason for someone not to do something deviant, the crime would occur and give way to neutralization as to why. In these cases, neutralizers would be able to identify the weakness in authority in their ability to neutralize. For example, kids on the playground are able to neutralize criticism by pointing out that their peer 'isn't their mother' or another person of authority. The reason this was not found in this analysis is because the forum posters were mostly defending piracy and thus there was not an opportunity to see this kind interaction. Had anti-piracy advocates been included in this forum, there is a chance these kind of informal sanctions could have played a role.

Previous research for software piracy has indicated that legal solutions are one of the most effective guardians in the digital age (Holsapple and Iyengar 2008). Despite this research's focus on media piracy, this notion is not only supported, it is expanded upon. The reason legal solutions are great guardians is because of their ability to have both high authority and high capacity, the second category of guardian qualities. Not only can the law inform someone what to do, it has the ability to command action. Potential deviants understand that if they do 
something against the law and get caught they are going to be formally sanctioned by the state.

These would be classified as 'capable guardians' by routine activates theory. Their high authority and capacity leaves little room for neutralizes to justify their actions.

In cases of piracy this no longer works as it does in the physical space. The pirates of this forum realized that the law is normally high authority and capacity but were able to neutralize based on the fact that law enforcement agencies have a difficult time tracking down pirates. In other words, the legal system becomes high authority and low capacity on the internet. One pirate said,

The government and the record industry together don't have enough thugs to stop them all. They'll be reduced to making gruesome examples of the few people they can go after (making themselves even more unpopular), while the rest proceed unhindered.

This is actually one of the results of the Napster case, but failed in its capacity to effectively demonstrate its ability to prosecute enough people. Had the record labels been able to sue all of the pirates during the Napster era, they would have retained high authority and high capacity.

Neutralizations that show the guardian as having high authority and low capacity would mean that the guardian give formal commands but have no way to elicit an action from a potential deviant. Because the guardian has the ability to command but not the ability to elicit action, neutralizers are able to utilize the lack of action in their neutralizations. In the case of digital piracy, this was seen when the forum posters talked about the record labels and RIAA as having the ability to punish them but not having any way to actually enforce punishment because of the sheer number of people committing the crime. This is exactly what was occurring in the previous example of exploiting the laws inability to catch them as well. While attempting to neutralize their behavior, one pirate said

There are already so many people [doing it], they can't just round you all up... And the penalties are potentially life-destroying. 
This poster recognizes the authority of the record labels but instantly identifies that they don't have the capacity to do anything about it. This fault of the guardian not only allowed the action to occur, but also way to neutralize for the deviant.

Low authority and low capacity guardians would be a complete failure of guardianship. The guardian's ability to either give a command or elicit action is essential to their ability to be capable. When a guardian is this ineffective, it almost does not even require neutralization. Many times, deviants are unaware that the guardians should even be affecting their action. An important aspect is not that there is an absence of guardianship; it's just that it is in effective. The record labels or legal system may have put it in place to act as a guardian but it does not deter crime or elicit neutralization. For Napster and digital piracy this was seen when the forum posters were discussing Napster's licensing agreement. They said, the licensing agreement [for Napster] is one of those where you have to hit a link to read it or you can just [skip it and] click "ok" instead, so everyone just clicks "ok"

The licensing agreement should carry authority and capacity to deter crime but no one really takes the time to actually read them. They are supposed to act as a guardian that warns against unlawful use but are unable to fulfill their guardianship roles because of their inability to get the command across combined with a failure in action.

The main difference between traditional techniques and the new ones identified in this research is, technology has created an anonymous environment that makes it difficult for active guardians to be effectively utilized. Whereas in the physical space we are able to create active guardians that deter potential deviants even if they see nothing wrong with the crime. For some it is the threat of being caught that deters, while for others it is the fact that whatever the action is, it is morally wrong. The only commonality is the high capacity to elicit action that deters 
crime. Because the internet makes it difficult to monitor action, we rely on guardians that 'selfmonitor.' Record labels have been trying to convey to pirates that stealing is wrong, and this is something that was picked up on by the pirates. One of them explained,

The battle must be won in the hearts and minds of the people, because short of shutting down the internet the technology makes the laws futile.

Technology makes it essential that the guardian at play have a high capacity, regardless of authority, because that is what pirates are most likely to attack. Law enforcement and the legal system do not have enough resources to combat piracy on this wide of a scale; there are simply too many people doing it. Passive guardianship is what helps deter crimes on the internet because they don't have the resources to actively deter crime.

Having low authority or low capacity gives deviants the opportunity to neutralize. They are able to leverage the weakness of the guardian in their neutralizations. As shown, crimes on the internet exploit low capacity because of their inability to actually catch pirates. Attacks of low authority could be seen in informal sanctions. Either way, having a low ability opens the path way of neutralization for pirates.

If the record labels were able to establish that piracy is morally wrong and the equivalent of theft, it could play into people's moral decision to pirate. Even if they are not able to get everyone to believe them, they could rely on informal sanctions of others to help further their cause. In this case, it would be hard to criticize their authority if the record labels have been successful in making it 'common sense' that piracy is illegal/immoral/bad. Despite having high authority guardians around, pirates seem the most reluctant when there is a potential to be caught and understand that low capacity guardians don't have that ability. One of the pirates said, the question for many people is not "is this illegal" but "can I get away with it 
Because of the lack of high capacity guardians, a large number of pirates have been able to get away with piracy for over a decade.

The traditional techniques of neutralization are not as complex when it comes to authority and capacity. No patterns emerged that suggested that specific combinations of authority and capacity had an effect on a specific neutralization. Both low capacity and low authority could be attacked in any of the neutralizations depending on the circumstances. Neither was more or less prevalent in neutralizations. The real difference between neutralizations is the reliance on active and passive guardianship. As the new techniques are mostly technologically related, they rely heavily on passive guardianship because traditional active gurdians do not translate to the internet very well.

These four typologies of guardianship show that the guardian's ability to demonstrate authority and capacity to potential deviants is connected to how deviants will later neutralize their behavior. Guardians must be able to understand how to create perceptions of authority and capacity if they wish to be capable guardians that deter crime from occurring.

\section{Improving Guardianship}

The focus of this thesis is the role guardianship plays in using techniques of neutralizations. These neutralizations are effective because they are a response to the guardians at play. When something is missing it allows a deviant to use the neutralization as a way to justify their behavior.

Neutralization is simply an excuse or justification based on the failure of the guardian. The guardian must correct these mistakes in order to make excuses harder to come by for the potential deviant and thus make it less likely that internet piracy will occur. A guardian can take many forms, some of which can be created by a third party. For instance, ad campaigns that want 
to promote a certain type of behavior will give drastic consequences for disobedience. If you wanted to stop drunk driving, flyers could be put up warning of the dangers and later when people drink they might remember what they saw, deterring their behavior. This type of guardian is clearly high authority and high capacity because of the message it sends while also managing the potential deviant's decision making process. If record labels, the government, and internet service providers wish to properly combat digital piracy they must create a system of guardianship that effectively removes the ability for a potential pirate to neutralize their behavior.

Policy makers should be interested on 'plugging the holes' in their attempts to generate successful guardians or being successful guardians themselves. Each technique requires something different and require a different guardian despite the situation. This thesis has drawn attention to different specific types of guardians but in reality there are an infinite number of things that deter people from committing crimes.

Although the items included for the traditional techniques of neutralization could also be applied to terrestrial crime, this focus is on digital piracy but there is no reason to think that the same general idea could not be applied to other types of crime. Knowing the justifications used can help authority figures create policies that target specific types of crime. There are five traditional techniques and understanding them can help improve guardianship.

Successful guardians for deviants who could claim denial of injury would have to establish that just making a copy hurts the artist or the record label. The music was something that was created and like other items people enjoy, should only be listened to after purchase or with appropriate permissions. Being able to demonstrate injury is key to enhancing authority and capacity. The denial of injury neutralization hinges on whether or not the pirates believe that a 
copy constitutes harm. For the record labels to restore capacity over the pirates they would need to establish that these copies are harming their business. Their greatest argument is that any unauthorized copy created is one less that would has been legitimately bought which clearly shows how widespread piracy can have an effect on the record labels. If they were to provide factual data that supported their claim of monetary losses by starting a campaign on the effects of piracy on their business, they might bring legitimacy to their claims of injury.

When pirates use condemning the condemners they are turning the tables on the both the record labels and demonstrate how guardians have failed. The distrust of the labels creates an instance where any authority and capacity they once held is negated. In many instances, if the record labels were to lower their prices and be more transparent with why the prices are set at what they are, the labels could rebuild this damaged relationship. This relationship is what created legitimacy to both their authority and capacity. When the deviant understand why something is happening, and accepts it, they will subvert back to the appropriate role and listen. As it stands now, record labels are getting a bad reputation for the way they deal with consumers. Although the fear of being sued for millions of dollars is a potential guardian, it is also serving to alienate everyone who isn't being sued. The pirating community is aware that the RIAA and labels do not have enough resources to sue everyone so in the end, suing potential customers is only back firing. Record labels would be wise to go on the offensive and develop new guardians that specifically detail their role in the music making process and why piracy is hurting their business and why music is sold at the price it is. They need to restore their authority and capacity by showing they are not just taking advantage of the consumer.

The way of creating an effective guardian for denial of responsibility is very similar to that of the previous neutralization. Even when law enforcement gained a moderate amount of 
authority and capacity they were met with an overwhelming number of pirates. Passive gurdians such as 'gaining respect' by admitting guilt are not necessarily effective because of how much its outweighed by the potential negative consequences. A potential alterative to the lawsuit could have been for Napster to talk to the government and work out a deal by claiming responsibility and creating a situation in which the benefits can out way the negative. Although this may seem farfetched, this kind of deal occurs quite frequently in our legal system. Criminals will claim responsibility for something because the attorney's office offers them a lighter punishment in exchange for information. In the case of Napster, they could have taken a slap on the wrist and worked with the RIAA and government to become the first 'digital retailer, similar to what iTunes provides for consumers now. Rather than a law suit, they would have created a multibillion dollar industry, saved face with the media, and turned a bad situation into something that could change digital music forever. Of course, none of this never actually happened. Instead they denied responsibility and were sued into oblivion, only to replicate iTunes type system years later that would later be sold to Rhapsody. For end users at the time, and contemporaneously, an education system would help create guardian's that would not allow them to deny responsibility. Hiding behind the cloak of not understanding, Napster was successful because reasonable attempts to educate the public on piracy were not yet attempted. If they knew that both parties were in the wrong and the potential outcomes, the guardian would have been successful at modeling behavior.

As criminologist and sociologist, we recognize the importance of neutralizations in justifying criminal behavior. For years, we have been studying the techniques originally discovered by Matza and Sykes, but this research supports the notion that there are different neutralizations used in the digital era that they could never have imagined. Understanding these 
new techniques early is important in creating effective policy. As it stands now, the internet is a place without much structure or opportunities for guardianship. With these suggestions for the new techniques as laid out in this thesis authority figures can take appropriate steps in creating effective guardians.

Deviants who utilize an out dated system neutralization use the differences between the physical and virtual settings that make traditional laws and policies obsolete. Because physical policies don't translate well to the digital environment, authority figures have to rely on another type of guardian. They need to become effective at creating moral guardians. This often occurs on college campuses in underage drinking awareness. Like the previous example, just putting up flyers and spreading knowledge of what they are doing and what the potential consequences are could be enough to deter the crime from occurring. Until that can occur, traditional guardians will continue to fail until it reaches the mind of the individual. One could say that encryption/DRM and other physically inspired guardians could work but the internet is a cat and mouse game. As someone said in the forum, the quickest way to get something done is to tell a hacker/geek it can't be done. The internet is a tricky place because hackers are usually extremely intelligent, self taught, and even recruited by the government. Because they understand exactly what they are doing, guardians such as DRM will continue to fail.

This thesis deals with phenomena that occurred over ten years ago and therefore some of the information may seem dated. For denial of access, many of the forum posters complied that there were no legitimate methods of acquiring the music. In this day and age, MP3 retailers are virtually everywhere on the internet and it is possible to purchase items that are 'out of print'. A more farfetched approach could be to reduce the price of MP3s below the market standard of one dollar per song. An effective guardian is anything that deters crime, so if a potential pirate 
thought the music they wanted was going to be available for a deep discount, they would be more likely to purchase it rather than pirate it. The record companies may not like the idea of selling their items at a heavy discount, but at least this way they would get some money rather than none. This type of approach would restore faith in the consumer/record label relationship and give more authority and capacity to the record labels.

In the sub-category lack of humanization, the guardianship can be improved similarly to that of condemning the condemners. The record labels seem to struggle to maintain relevance and connection to the consumer and are unable to utilize effective press relations. They may not be able to leverage themselves very well to the consumer and create the connection that stops piracy, but they can utilize the artist to sell music. Not all artists have millions of dollars, and I would argue it's even more successful for lower income artists, and when they label themselves as a victim. It makes the potential pirate 'feel bad' and they don't go through with it. The more of a connection they have the less likely they are to do it. The artist is sometimes forgotten in the heat of the moment, because most of publicity goes to how the record labels are affected. Many don't believe that artists really get any of the money so it doesn't really matter what is taken from the label. Records can be taken from the company without guilt but there are ways to directly compensate the artist by going to shows, buying merchandise, etc. Demonstrating the complex relationship between the record labels and artist would allow them to demonstrate how the artist is injured through internet piracy. This would probably not be as successful as the artist alone combating piracy but still would 'poke holes' in the denial of access neutralization.

For the guardians at play in ambiguity of the law to be successful they must prove beyond a reasonable doubt that IP theft is the same thing as normal theft. These definitional differences are what create this neutralization so an effective guardian would be able to nullify these 
concerns. Once this idea is established, it can then be treated in the same manner which will include the normal guardians that play into crime. The inherent different between the two mediums clouds the judgment of the typical user and because they never actually feel the item, or have any other real indication they took it, they do not consider it to be theft.

Denial of law is one of the neutralizations that the labels and legislators technically have the most control over. This neutralization attempts to hinge off of the idea that the law must be rational and serve the purpose, which may be true but not as a neutralization. The law as a guardian has proven to be pretty successful for hundreds of years, but there are always people who will commit crime regardless of the guardians at place. For this neutralization to have been more effective it would have had to add a justification that would mostly resemble an appeal to higher loyalties. If they were to make the case that copyright laws inhibit the free spread of ideas and data and that they will disobey the law until something they accept is created, it could have worked. Something like this would have spoken to what they disagree with and how it has a broader effect. They would have made the case that they are disobeying the law to bring attention that a solution is needed that is more beneficial to society.

\section{CONCLUSION}

Recently, congressional bills such as the Stop Online Piracy Act (SOPA) and Protect Intellectual Property Act (PIPA) have attempted to create digital piracy law. Although the government is considering the issue, they did it in such a way that it would have crippled the internet experience in the United States. It is a difficult issue to tackle, but these laws were largely viewed as too severe. Rather than take such a brute force method the government should invest more in research to create innovative solutions for an ever changing problem. This research has suggested that the connection between guardianship and piracy could allow the 
government to create laws and policy that could effectively stomp out piracy for the general public. Reducing the ways in which someone can neutralize will make it difficult for the normal law abiding citizen to commit piracy.

This research looked at particular guardians used in these several different neutralizations. There are clearly more guardians at play than what are listed, but these guardians are the ones that neutralization really takes advantage of. If policy makers wish to create an effective policy they should consider improving their business and the laws accordingly so that deviants do not have an opportunity to use these types of techniques. Once the authority figures are able to establish that piracy and intellectual property theft is clearly a crime, without a reasonable doubt and convict pirates they will not only have successfully implemented these ideas but also created a new guardian.

This new guardian is that of being caught and dealing with the consequences of their actions. As it stands right now people are able to take advantage of the system because they know that the worse that will happen is they will get a cease and desist letter from their Internet Service Provider and little more. Certainly clear and unavoidable punishment would add another guardian that is able to prevent pirates from abusing the system.

One of the most important things that congress could do to combat digital piracy is to educate the public on what exactly digital piracy is, who can get in trouble, how it affects the industry, and how digital piracy has a much bigger impact than just the record labels alone. Previous research has shown that college aged males are most likely to commit digital piracy, so these education programs could start on college campuses and expand. Introduction to university classes could implement these topics into their education about the university, especially since in many cases it is the universities who are paying the bill for the student's mistakes. Morals are a 
great passive guardian because for most people they carry high authority and high capacity, the two things that create a capable guardian. In the lawless 'wild west' of the internet the government and record labels need to eliminate any guardianship failures that lead to neutralization. 


\section{References}

Ahmad, Noor, Lau Guek Chin, May-Chiun Lo, and T. Ramayah. 2009. "Testing a Casual Model of Internet Piracy Behavior Among University Students." European Journal of Scientific Research 29.2: 206-214.

Brune, Rebecca, Tim Goles, and Beena George. 2008. "Softlifting: Exploring Determinants of Attitude." Journal of Business Ethics 2008.77: 481-499.

Cheng, Hsing, and Ronald Sims. 1996. "Toward a Profile of Student Software Pirates." Journal of Business Ethics 15.8: 839-849.

Crittenden, William, K.M. Gilley, and Christopher Robertson. 2008. "Trade Liberation, Corruption, and Software Piracy." Journal of Business Ethics 78.623: 623-634.

Cronan, Timothy, and Sulaiman Al-Rafee. 2008. "Factors that Influence the Intention to Pirate Software and Media." Journal of Business Ethics 78.527

Delany, Paul. 1995. “The Discourse of Computer-Supported Media: Reading and Writing on Usenet." Modern Humanities Research Association: 213-224.

Dent, Christopher. 2009. "Copyright As (Decentered) Regulation: Digital Piracy As a Case Study." Monash University Law Review 35.2: 348-375.

Easly, Robert. 2005. "Ethical Issues in the Music Industry: Response to Innovation and Piracy." Journal of Business Ethics 62.2 (2005): 163-168.

Eining, Martha, and Darryl Woolley. 2006. "Software Piracy among Accounting Students: A Longitudinal Comparison of Changes and Sensitivity." Journal of Information Systems 20.1: 4963 . 
Fream, Anne, and William Skinner. 1997. "A Social Learning Theory Analysis of Computer Crime Among College Students." Journal of Researching Crime and Delinquency 35.495

Freestone, O., and V. W. Mitchell. 2004. "Generation Y Attitudes Towards E-Ethics and Internet-Related Misbehaviors." Journal of Business Ethics 54.2: 121-128.

Givon, Moshe, and Vijay Mahajan. 1995. "Software Piracy: Estimation of Lost Sales and the Impact on Software Diffusion." Journal of Marketing 59.1: 29-37

Gupta, Pola, and Stephen Gould. 2004. "To Pirate or Not to Pirate: A Comparative Study of the Ethical versus Other Influences on the Consumers Software Acquisition-Mode Decision." Journal of Business Ethics 55.3: 255-274.

Higgins, George, and David Makin. 2004. "Does Social Learning Theory Condition the Effects of Low Self-Control on College Students' Software Piracy?." Journal of Economic Crime Management 2.2

Holsapple, Clyde, Haihao Jin, and Shashank Rao. 2008. "Parameters for Software Piracy Research." Information Society 24.3: 199-218.

Haq, Husana. 2012. "Encyclopedia Britannica Puts an End to Print Publishing.” The Christian Science Monitor March 14

Hui Lee, Hsin, 2005 . "Antecedents of Music Piracy Attitudes and Intentions." Journal of Business Ethics 57.2: 161-174.

Hopton, John. 2007. "Mixed Martial Arts and Internet Forums: A Case Study in Treating Internet Sources as Oral History." Oral History, 35.2:91-99

Huberman, Michael and Matthew Miles, ed 1994. Qualitative Data Analysis: An Expanded Sourcebook. $2^{\text {nd }}$ ed. Washington D.C.: Sage Publications Inc. 
Husted, Bryan. 2000. "The Impact on National Culture on Software Piracy." Journal of Business Ethics 26.3: 197-211.

Khouja, M, and HK Rajagopalan. 2009. "Can Piracy Lead to Higher Prices in the Music and Motion Picture Industry?." Journal of Operational Research Society 60: 372-383.

Machado Fernando, Collin, Sellman, and Rajiv Sinha. 2010. 'Don't Think Twice, It's All Right: Music Piracy and Pricing in a DRM- Free Environment.” Journal of Marketing 74.3: 4054

Nichols, Lawrence. 1997. "Social Problems as Landmark Narratives: Bank of Boston, Mass Media and Money Laundering” Social Problems, 44.3:324-341

Piquero, Nicole, and Alex Piquero. "Democracy and Intellectual Property: Examining Trajectories of Software Piracy." 2006. Annals of the American Academy of Political and Social Science 605.5: 104-127.

Pound, Roscoe. 1964. "The Need of Sociological Jurisprudence” Crime \& Delinquency 10.4:385-397

Yar, Majid. 2005. "The Novelty of 'Cybercrime' An Assessment in Light of Routine Activities Theory." European Journal of Criminology 2.4: 407-427. 